\title{
Recent advances with association models for practical applications
}

Tsivintzelis, loannis; Bjørner, Martin Gamel; Kontogeorgis, Georgios M.

Published in:

Molecular Physics

Link to article, DOI:

$10.1080 / 00268976.2018 .1465604$

Publication date:

2018

Document Version

Peer reviewed version

Link back to DTU Orbit

Citation (APA):

Tsivintzelis, I., Bjørner, M. G., \& Kontogeorgis, G. M. (2018). Recent advances with association models for practical applications. Molecular Physics, 116(15-16), 1921-1944 .

https://doi.org/10.1080/00268976.2018.1465604

\section{General rights}

Copyright and moral rights for the publications made accessible in the public portal are retained by the authors and/or other copyright owners and it is a condition of accessing publications that users recognise and abide by the legal requirements associated with these rights.

- Users may download and print one copy of any publication from the public portal for the purpose of private study or research.

- You may not further distribute the material or use it for any profit-making activity or commercial gain

- You may freely distribute the URL identifying the publication in the public portal

If you believe that this document breaches copyright please contact us providing details, and we will remove access to the work immediately and investigate your claim. 


\title{
Recent advances with association models for practical applications
}

\author{
Ioannis Tsivintzelis ${ }^{1,2}$, Martin Gamel Bjørner ${ }^{1}$, and Georgios M. Kontogeorgis ${ }^{1}$ \\ ${ }^{1}$ Center for Energy Resources Engineering (CERE), Department of Chemical and \\ Biochemical Engineering, Technical University of Denmark, Building 229, DK-2800, \\ Denmark \\ ${ }^{2}$ Department of Chemical Engineering, Aristotle University of Thessaloniki, 54124 \\ Thessaloniki, Greece.
}

Keywords: Association models, CPA, SAFT, Enthalpy, Glycols, $\mathrm{CO}_{2}$

\begin{abstract}
Association models like CPA and other SAFT variants have found widespread use, especially over the recent 30 or so years, and this is not limited any more to universities and researchers. Industry is beginning slowly to adopt such models for some applications and a few of the association models are now provided by commercial simulators. Association models account explicitly for hydrogen bonding (and other complex) phenomena and for this reason they are potentially more useful and more successful than traditional models like cubic equations of state and activity coefficient models. Still, for practical applications all models are judged by their results and these depend on availability of experimental data, the number and type of adjustable parameters and the performance of the models for phase equilibria and occasionally also for other properties. We will consider four case studies in this work which will illustrate some of the capabilities and limitations of these association models in different applications. We will offer a "model developer's" point of view showing in several cases all stages of model development in order to illustrate what worked, what didn't and how it was corrected (when possible). The "physics" and "application" aspects of the models will be in all cases discussed. All results will be shown with the CPA equation of state, although we expect that the overall conclusions will be the same for a wide range of association models.
\end{abstract}




\section{Introduction and motivation}

Association models like those belonging to the SAFT family have received increasing attention over the last 30 years. While in terms of citations, PC-SAFT proposed by Gross and Sadowski [1] is the most popular version (over 1200 total citations and more than 70 per year; source Web-of-Science, July 20, 2017), other SAFT variants have also received widespread use e.g. soft-SAFT [2] and SAFT-VR and SAFT-gamma-Mie [3].

These association models, often expressed in the form of non-cubic equations of state, contain typically 5 (sometimes more) parameters for pure associating compounds and 1-2 adjustable interaction parameters for each binary mixture. They account explicitly for hydrogen bonding (association) phenomena, and for some of these models also for other effects e.g. polarity. Their applications range from systems of relevance to petroleum and chemical industries up to polymers, pharmaceuticals and even biotechnology.

This manuscript is not a review of these association models, neither their many applications; the interested reader can consult the original publications, recent monographs [4-6] and also a number of review manuscripts e.g. by Kontogeorgis [7] and Economou and Kontogeorgis [8] as well as by Muller \& Gubbins [9] and by Economou [10].

In this manuscript we will present some recent advances of these association models especially related to practical applications. Because of this, particular emphasis will be paid to the number and type of adjustable parameters used during the model development and on how the models are validated, i.e. how their predictive performance is assessed. A comparison of many different models may be difficult, but it may not be necessary. We believe that, as shown in a number of studies [11-14] the differences between the various association models are rather small and the models typically perform rather similarly. By this we mean that when tested over a range of systems and conditions and when the models are parameterized in the same way (e.g. having same number and type of adjustable parameters), the difference in the overall models performance is small.

For this reason, all results shown here will be presented with the CPA equation of state [15], a model based on a cubic equation of state e.g. SRK and the association term of SAFT. The model has received quite some attention in the literature since its appearance more than 20 years ago and the references shown earlier provide both the equations and several applications. New advances will be presented in this work and we believe that most of the conclusions can be transferred or applied to other association models as well. In this work we limit ourselves to non-electrolyte systems as electrolyte solutions require additional considerations and we have offered a recent review elsewhere [16]. 


\section{Case study I: The role of excess enthalpy data in the parameter estimation}

The first topic we consider is the potential role of excess enthalpy $\left(H^{E}\right)$ data in parameter estimation. While phase equilibria data (often VLE or LLE) are typically used in the estimation of adjustable parameters of models and their validation, excess enthalpies are rarely considered, neither in the fitting nor in the assessment of the predictive capabilities of the models. This is, of course, not correct as such information is important in many practical applications but also because advanced association models, also due to their larger number of parameters, should embrace a larger number of applications and could accommodate a larger number of experimental data.

As an example, here, we will consider first the binary systems methanol - dimethyl carbonate (DMC) and methanol-water and how their parameters can be estimated using both VLE and excess enthalpy data (or only VLE data). For both cases, the predictive ability of the model will be then evaluated by comparing CPA predictions for the VLE of various multicomponent systems containing these compounds. In all cases, pure fluid parameters were adopted from Tsivintzelis et al. [17,18].

\subsection{Binary parameters obtained using VLE and $H^{E}$ data}

Initially, the binary parameters were estimated using either only VLE experimental data (case A) or both VLE and excess enthalpy data (case B). In all cases bubble-point calculations were performed for estimating the VLE, i.e. temperature and liquid compositions were set, while vapor pressures and vapor compositions were calculated. In case $\mathrm{B}$, the objective function was the sum of the average absolute deviations in vapor pressures, vapor compositions and excess enthalpies. The obtained binary parameters are presented in Table 1 . The CR-1 rule [19] was applied for water - methanol cross association, while DMC was modeled assuming one negative site that is able to cross associate with methanol (solvation) and using the modified CR-1 rule [19] for obtaining the cross association parameters. Consequently, for methanol - DMC, two adjustable parameters were used for both cases ( $k_{i j}$ and $\beta_{\text {cross }}$ ). For methanol-water, the binary interaction parameter $\left(k_{i j}\right)$ is the only adjustable binary parameter in case $\mathrm{A}$. On the contrary, for case B of the same system, there are three adjustable parameters $\left(k_{i j}, \varepsilon_{\text {cross }}, \beta_{\text {cross }}\right)$. The use of three adjustable parameters was required in order to obtain a reasonable correlation of the excess enthalpy data.

For the methanol - DMC system, VLE data exist in a wide temperature range (313-428 K) [20, 26], while excess enthalpy data exist only for 313.15 K [20]. The CPA correlations using both cases of Table 1 are presented in Figures 1 and 2. Using the binary parameters of case A, the model accurately describes the VLE of this system. However, as shown in Figure 2, the model overpredicts the excess enthalpy data. For case B, where the excess enthalpy data were included in the parameter estimation, the model satisfactorily describes both the VLE and the calorimetric data. 
Table t1. Binary parameters for methanol - water and methanol - DMC systems using experimental VLE data (case A) and both VLE and excess enthalpy data (case B).

\begin{tabular}{|c|c|c|c|c|c|c|c|}
\hline \multirow{2}{*}{ Mixture } & \multirow{2}{*}{$\begin{array}{c}\text { Temp. } \\
\text { Range K }\end{array}$} & \multirow{2}{*}{$k_{i j}$} & \multicolumn{2}{|c|}{$\begin{array}{l}\text { Parameters for the cross } \\
\text { association }\end{array}$} & \multirow{2}{*}{$\begin{array}{c}\% \mathrm{AAD}^{\mathrm{a}} \\
\text { in } \mathrm{P}\end{array}$} & \multirow{2}{*}{$\begin{array}{c}\% \mathrm{AAD}^{\mathrm{a}} \\
\text { in } \mathrm{y}_{2}\end{array}$} & \multirow{2}{*}{$\begin{array}{l}\% \mathrm{AAD}^{\mathrm{a}} \\
\text { in } \mathrm{H}^{\mathrm{E}}\end{array}$} \\
\hline & & & $\begin{array}{c}\varepsilon^{A_{i} B_{j}} \\
\left(\mathrm{~L} \mathrm{bar} \mathrm{mol}{ }^{-1}\right)\end{array}$ & $\beta^{\text {cross }}$ & & & \\
\hline \multirow[b]{2}{*}{$\begin{array}{l}\text { Methanol (1) - } \\
\text { Water (2) }\end{array}$} & \multirow{2}{*}{$\begin{array}{l}298-548 \\
(\text { VLE) } \\
278-523 \\
\text { (excess } \\
\text { enthalpies) }\end{array}$} & Case A: -0.0748 & CR-1 ${ }^{\text {b }}: 206.2$ & $\begin{array}{l}\text { CR-1 }{ }^{\mathrm{b}}: \\
0.0334\end{array}$ & 3.3 & 5.1 & 109 \\
\hline & & Case B: -0.1251 & 217.5 & 0.1822 & 4.6 & 4.0 & 31.9 \\
\hline \multirow{2}{*}{$\begin{array}{l}\text { Methanol (1) - } \\
\text { DMC (2) }\end{array}$} & \multirow[b]{2}{*}{$\begin{array}{c}313 \\
\text { (excess } \\
\text { enthalpies) }\end{array}$} & Case A: 0.0898 & $\begin{array}{c}\mathrm{mCR}-1^{\mathrm{b}}: \\
123.0\end{array}$ & 0.3286 & 2.7 & 7.1 & 78.6 \\
\hline & & Case B: 0.0302 & $\begin{array}{c}\mathrm{mCR}-1^{\mathrm{b}}: \\
123.0\end{array}$ & 0.1135 & 4.3 & 10.8 & 3.7 \\
\hline
\end{tabular}

${ }^{\mathrm{a}} \% \mathrm{AAD}=\frac{1}{n} \sum_{i}\left|\frac{X_{i}^{c a l}-X_{i}^{\text {exp }}}{X_{i}^{\exp }}\right| \times 100$ where and $n$ is the number of experimental data points and $X$ stands for property of interest (vapor pressure $P$, or vapor phase mole fraction, $y$, or excess enthalpies, $H^{E}$, in this Table). binary parameter calculated through the CR-1 or mCR-1 combining rule (not adjusted to the experimental data).

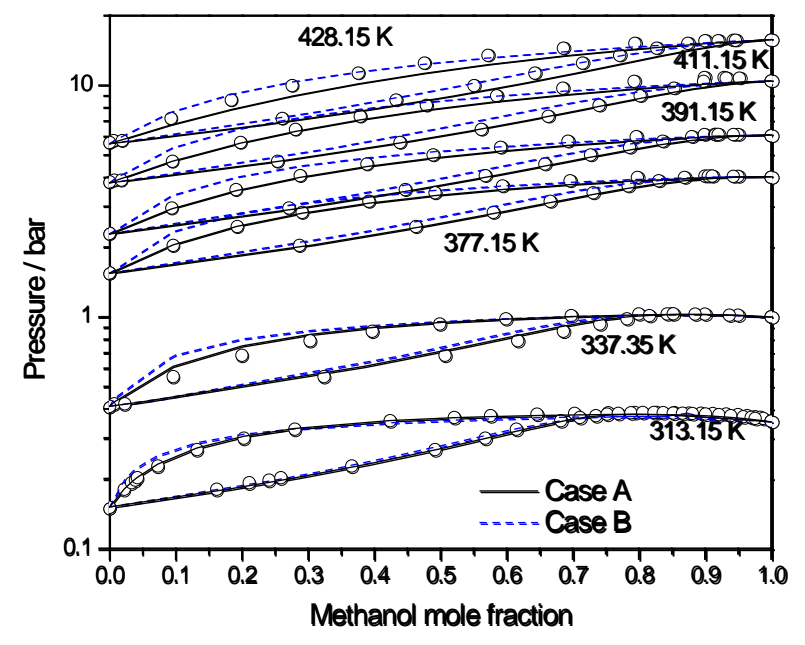

Figure 1. Methanol - DMC VLE. Experimental data (points from references 20 and 26) and CPA calculations (lines). 


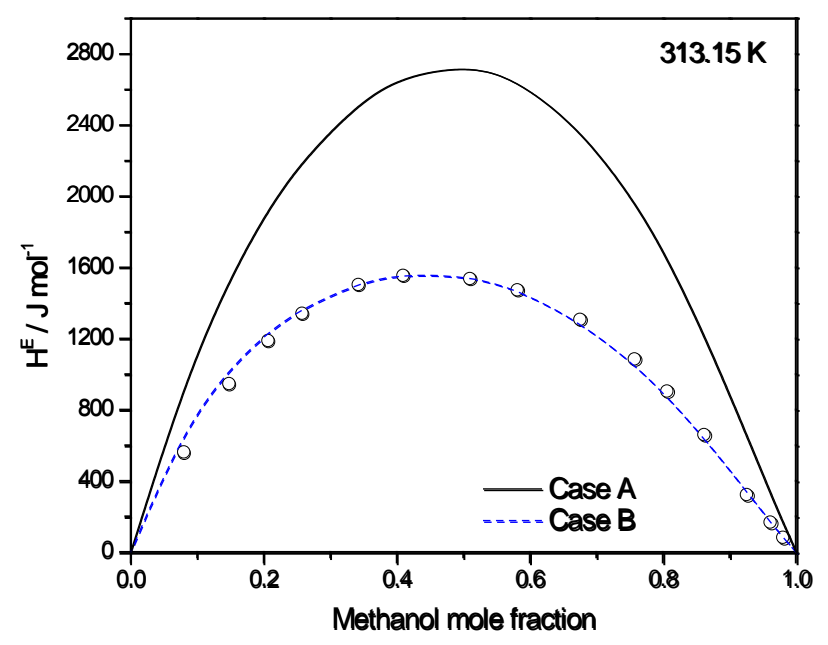

Figure 2. Methanol - DMC enthalpies of mixing. Experimental data (points from reference 20) and CPA calculations (lines).

For the water - methanol system, both VLE and excess enthalpy data exist over a wide temperature range. Mixing of water and methanol is exothermic at low temperatures $\left(\Delta H^{\text {mix }}<0\right)$, while it becomes endothermic $\left(\Delta H^{m i x}>0\right)$ at higher temperatures. Such complex behavior can be attributed to the association behavior of this system and the corresponding enthalpies of hydrogen bonding interactions. Consequently, for the accurate description of the excess enthalpies in that system, the hydrogen bonding behavior should be accurately captured. Using the parameters of the first case (case A), the model accurately describes the VLE (Figure 3a), while it is not able of an accurate description of the excess enthalpies (Figure 3b-c). This is somehow expected, since the cross hydrogen bonding parameters are obtained using a combining rule (CR-1), which has a limited physical base. For this reason, the use of the CR-1 rule was abandoned in case B and the cross association parameters were simultaneously fitted with the $k_{i j}$ to the experimental VLE and excess enthalpy data. In this way, the model satisfactorily describes the VLE (Figure 3a), while the model correlations for the $H^{E}$ are more reasonable (Figure $3 \mathrm{~b}-\mathrm{c}$ ).

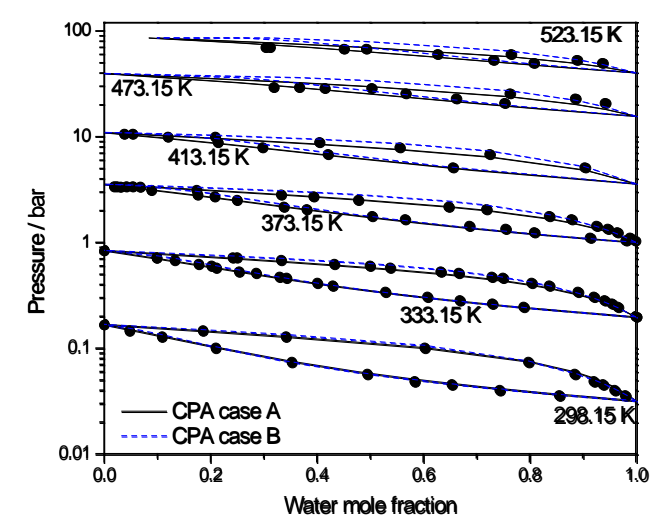

(a)

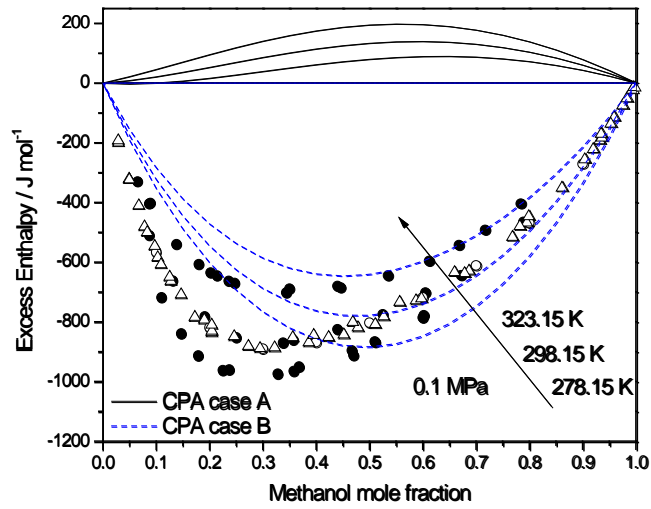

(b) 


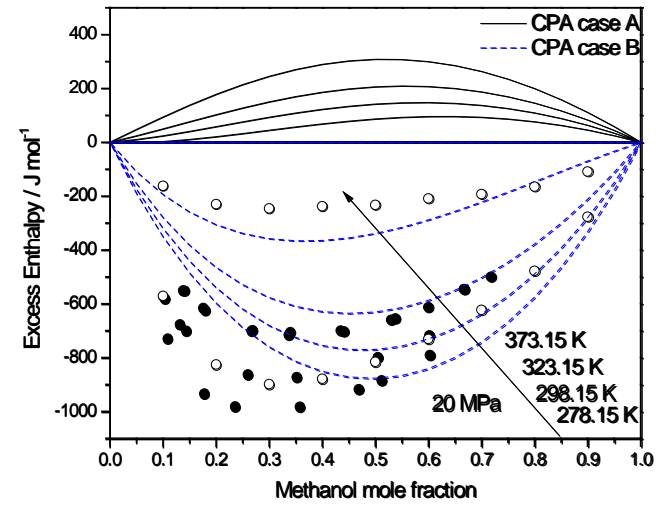

(c)

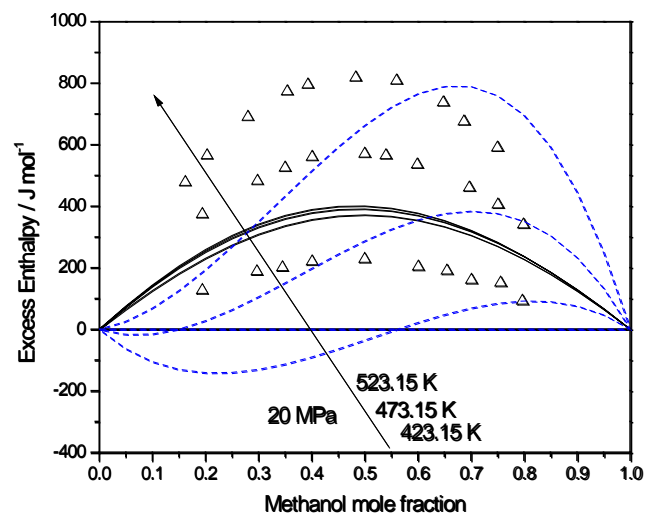

(d)

Figure 3. Methanol - water VLE (a) and enthalpies of mixing (b-c). Experimental VLE data are from references 21-25. Experimental $H^{E}$ data are from references 27-33.

\subsection{Multicomponent systems}

Having obtained the binary parameters from the binary systems, the model was applied to predict the phase behavior of various ternary systems using both cases of Table 1 and the binary parameters (for the remaining of the sub-binary mixtures) of Table 2. $\mathrm{CO}_{2}$ and DMC were modelled assuming that they have one site that is only able to cross associate with other hydrogen bonding fluids (solvation), such as water or methanol. For mixtures of $\mathrm{CO}_{2}$ with water or methanol the experimental values of the cross association energy were used [19]. In all cases flash calculations were performed using the middle of the experimental tie lines as feed compositions.

Table 2. Binary parameters for binary systems used in model predictions for multicomponent mixtures.

\begin{tabular}{|c|c|c|c|c|}
\hline \multirow[b]{2}{*}{ Mixture } & \multirow[b]{2}{*}{$k_{i j}$} & \multicolumn{2}{|c|}{ Parameters for the cross association } & \multirow[b]{2}{*}{ Ref. } \\
\hline & & $\begin{array}{l}\varepsilon^{A_{i} B_{j}} \\
\left(\mathrm{~L} \mathrm{bar} \mathrm{mol}^{-1}\right)\end{array}$ & $\beta^{\text {cross }}$ & \\
\hline $\mathrm{CO}_{2}-$ Water & 0.1141 & $\operatorname{Exp}^{\mathrm{a}}: 142.0$ & 0.0162 & [19] \\
\hline $\mathrm{CO}_{2}-$ Methanol & 0.0479 & $\operatorname{Exp}^{\mathrm{a}}: 123.8$ & 0.0196 & [19] \\
\hline Water - DMC & -0.0376 & $\mathrm{mCR}^{\mathrm{b}}{ }^{\mathrm{b}}: 83.27$ & 0.5055 & [17] \\
\hline Water - Methane & 0.0098 & - & - & [34] \\
\hline Methanol - Methane & 0.0528 & - & - & [35] \\
\hline $\mathrm{CO}_{2}$ - Methane & 0.0882 & - & - & [19] \\
\hline
\end{tabular}

${ }^{\mathrm{a}}$ Binary parameter adopted from experimental or theoretical data (not adjusted to the experimental data).

${ }^{\mathrm{b}}$ Binary parameter calculated through the mCR-1 combining rule (not adjusted to the experimental data). 
Initially, the LLE of water - methanol - DMC, was investigated using both cases A and B from Table 1. The results are presented in Table 3 and are illustrated in Figure 4, from where it is concluded that the binary parameters of case B result in more accurate predictions.

Table 3. Average Absolute Deviations (\%AAD) of model predictions from experimental data for DMC (1) - methanol (2) - water (3) LLE.

\begin{tabular}{|l|l|l|l|l|l|l|}
\hline & $\begin{array}{l}\text { \%AAD } \\
\text { in } \mathrm{x}_{1}\end{array}$ & $\begin{array}{l}\text { \%AAD } \\
\text { in } \mathrm{x}_{2}\end{array}$ & $\begin{array}{l}\text { \%AAD } \\
\text { in } \mathrm{x}_{3}\end{array}$ & $\begin{array}{l}\text { \%AAD } \\
\text { in } \mathrm{x}_{1}\end{array}$ & $\begin{array}{l}\text { \%AAD } \\
\text { in } \mathrm{x}_{2}\end{array}$ & $\begin{array}{l}\text { \%AD }^{\mathrm{a}} \\
\text { in } \mathrm{x}_{3}\end{array}$ \\
\hline Case $\mathrm{A}$ & 54.5 & 4.7 & 3.7 & 14.1 & 7.5 & 22.5 \\
\hline Case B & 42.7 & 4.6 & 3.1 & 8.5 & 5.8 & 13.3 \\
\hline
\end{tabular}

${ }^{\mathrm{a}} \mathrm{AAD}$ as defined in the footnote of Table 1

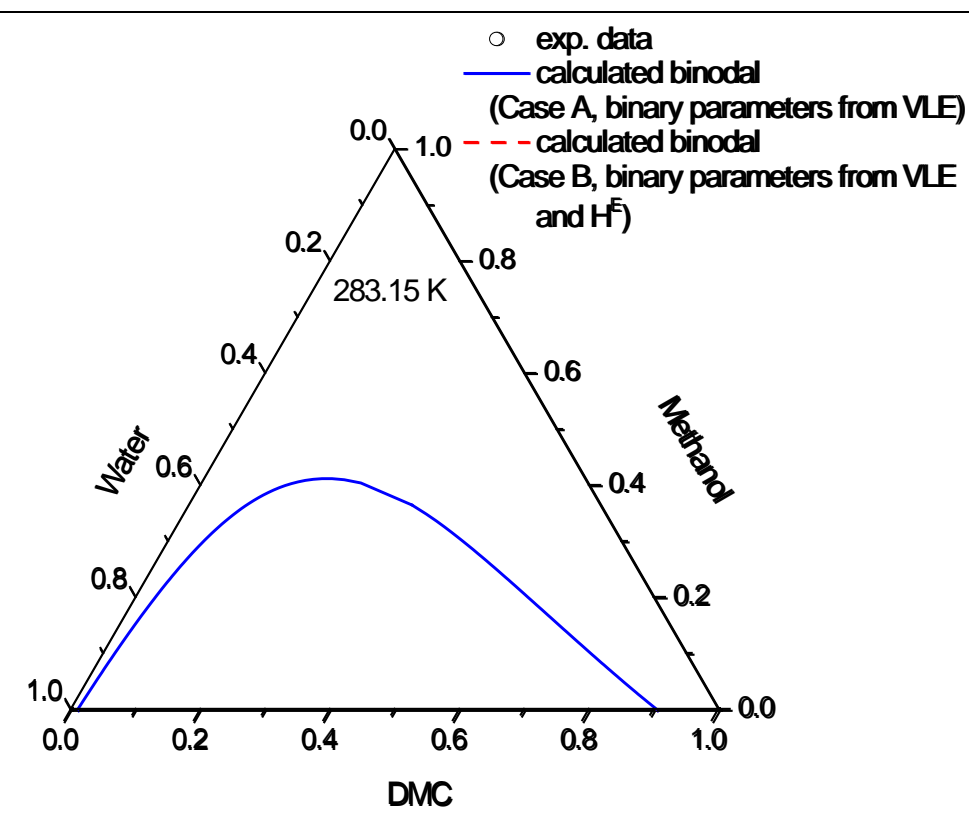

Figure 4. DMC - Methanol - Water LLE

Next the model was applied to predict the VLE of water - methanol - $\mathrm{CO}_{2}$ ternary mixture and the VLE of the water - methanol $-\mathrm{CO}_{2}-$ methane quaternary mixture. The results for the first (ternary) mixture are presented in Table 4, Figure 5 and in Figure S1 of the supporting information file. The results for the latter (quaternary) mixture are presented in Table 5. In both cases, using the binary parameters of case B for water - methanol, the model more accurately predicts the equilibrium compositions of the liquid phase. However, in both cases, the deviations of model predictions from the experimental data for the vapor phase compositions are considerably higher. 
Table 4. Water (1) - methanol (2) - $\mathrm{CO}_{2}$ (3), ( $\mathrm{T}=313.15 \mathrm{~K}, \mathrm{P}=70,100,120$ bar), VLE

\begin{tabular}{|l|l|l|l|l|l|l|}
\hline Case & $\begin{array}{l}\text { \%AAD } \\
\text { in } \mathrm{x}_{1}\end{array}$ & $\begin{array}{l}\text { \%AAD } \\
\text { in } \mathrm{x}_{2}\end{array}$ & $\begin{array}{l}\text { \%AAD } \\
\text { in } \mathrm{x}_{3}\end{array}$ & $\begin{array}{l}\text { \%AAD } \\
\text { in } \mathrm{y}_{1}\end{array}$ & $\begin{array}{l}\text { \%AAD } \\
\text { in } \mathrm{y}_{2}\end{array}$ & $\begin{array}{l}\text { \%AAD } \\
\text { in } \mathrm{y}_{3}\end{array}$ \\
\hline $\mathrm{A}$ & 8.9 & 7.2 & 48.1 & 43.6 & 24.7 & 1.0 \\
\hline B & 5.5 & 5.2 & 24.2 & 63.9 & 83.0 & 3.1 \\
\hline
\end{tabular}

${ }^{\mathrm{a} A A D}$ as defined in the footnote of Table 1

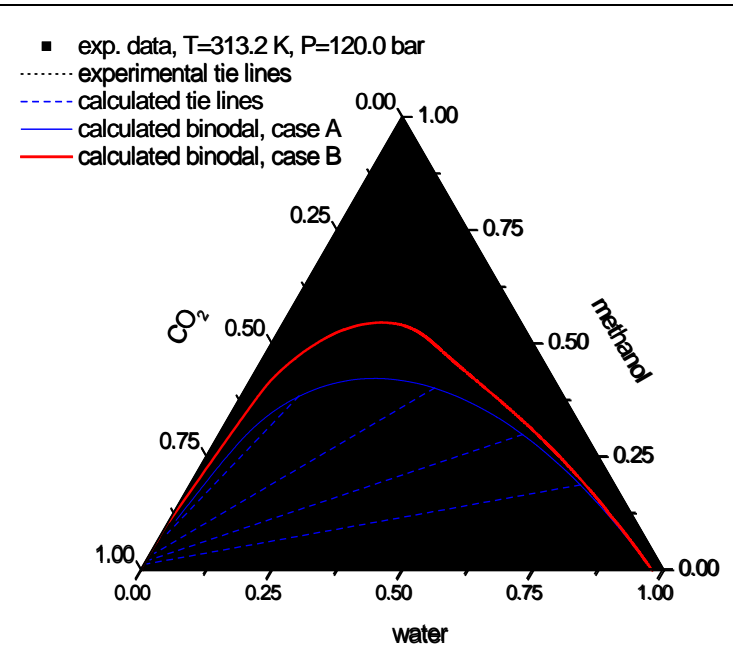

Figure 5. Water - methanol - $\mathrm{CO}_{2}$ VLE. Experimental data [36] and CPA predictions.

Table 5. Deviations of model predictions from experimental data for Water (1) - Methanol (2) $-\mathrm{CO}_{2}$ (3) - Methane (4) VLE

\begin{tabular}{|c|c|c|c|c|c|c|c|c|}
\hline & $\mathbf{x}_{1}$ & $\mathbf{x}_{2}$ & $\mathbf{x}_{3}$ & $\mathbf{x}_{4}$ & $\mathbf{y}_{1}$ & $\mathbf{y}_{2}$ & $\mathbf{y}_{3}$ & $\mathbf{y}_{4}$ \\
\hline \multicolumn{9}{|l|}{ Case A } \\
\hline$\Delta x^{a}$ & 0.2836 & 0.1538 & 0.1742 & 0.2632 & 0.0159 & 0.0163 & 1.0236 & 1.0494 \\
\hline$\% \mathrm{AAD}^{\mathbf{b}}$ & 0.39 & 0.59 & 36.30 & 55.62 & 26.19 & 14.25 & 10.81 & 1.16 \\
\hline \multicolumn{9}{|l|}{ Case B } \\
\hline$\Delta \mathbf{x}^{\mathrm{a}}$ & 0.1945 & 0.0661 & 0.0964 & 0.1643 & 0.0255 & 0.1665 & 0.8082 & 1.0000 \\
\hline$\% \mathrm{AAD}^{\mathrm{b}}$ & 0.26 & 0.25 & 20.85 & 35.63 & 39.01 & 98.31 & 8.44 & 1.11 \\
\hline
\end{tabular}

${ }^{\mathrm{b}} \mathrm{AAD}$ as defined in the footnote of Table 1

The model was also applied to predict the bubble points of $\mathrm{CO}_{2}$ - water - methanol -methane system using the experimental data from another source. For this system, Jarne et al. [37] measured the bubble points of mixtures that contain a very small amount of water and methanol, while they are rich in methane and $\mathrm{CO}_{2}$. The mole fraction composition of a representative mixture is $x_{\text {water }}=0.00019, x_{\text {methanol }}=0.00180, x_{\mathrm{CO} 2}=0.19960, x_{\text {methane }}=0.79841$. Such mixtures are in a single phase (vapor) at low pressures and present VLE as the pressure increases as shown in Figure 6. 
Using the binary parameters of case A, the model overpredicts the bubble points, but the description is considered satisfactory. Using the binary parameters of case $\mathrm{B}$, the model seriously under-predicts the bubble points. The same conclusions were obtained for similar data for the mixtures of water - methanol $-\mathrm{CO}_{2}$ with ethane, propane and butane.

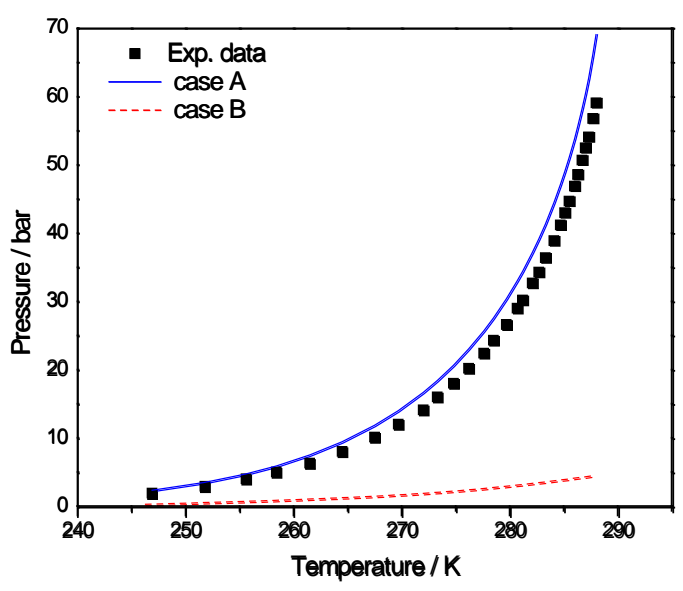

Figure 6. Bubble points of the quaternary $\mathrm{CO}_{2}$ - water - methanol -methane system $\left(\mathrm{x}_{\text {water }}=0.00019, \mathrm{x}_{\text {methanol }}=0.00180, \mathrm{x}_{\mathrm{CO} 2}=0.19960, \mathrm{x}_{\text {methane }}=0.79841\right)$

In conclusion, from the ternary and quaternary systems studied, it is concluded that the adoption of the binary parameters of case B (obtained using $H^{E}$ data) result in more accurate description for the liquid phase, but in serious deviations from experimental data for the vapor phase. For mixtures that contain water and methanol, such behavior can be attributed to the strong cross-association interactions. The use of relatively high values for the cross association parameters of case $\mathrm{B}$, force the model to under-predict the water and methanol content of the vapor phase in such low temperatures resulting in a serious failure in the description of the vapor phase.

\section{Case study II: The role and importance of adjustable parameters in association models}

The second case-study is related to the role and importance of adjustable parameters in association models when the target is the simultaneous representation of multiple properties. We will illustrate this using CPA for the modeling of the triethylene glycol (TEG)-water mixture, which is of importance to many practical applications. For this mixture there are extensive VLE, SLE data as well as excess enthalpies and activity coefficients at finite concentrations and infinite dilution.

\subsection{Literature parameters}

Systems of TEG that are relevant to the oil and chemical industry were previously studied by Breil and Kontogeorgis [38]. The authors made a thorough investigation of the 
thermodynamic modeling of mixtures that contain TEG with water, aliphatic and aromatic hydrocarbons using the CPA equation of state. TEG molecule was modeled as a selfassociating fluid using the well-known, according to the classification of Huang and Radosz [39], 4C association scheme (where two proton donors and two proton acceptors are assumed on every molecule), as well as the newly developed 6D scheme (where two proton donors and 6 proton acceptors, all equivalent for simplicity, were assumed on every TEG molecule) [38]. Based on such association schemes three pure fluid parameter sets (sets 1-3) are reported for TEG, which are shown in Table 6. The parameter set 1 was obtained by fitting the predictions of the model to vapor pressure and liquid density data from the DIPPR correlations [40]. The parameter sets 2 and 3 were obtained by including in the parameter estimation, except from vapor pressure and liquid density data, binary data for the vaporliquid equilibrium for TEG-methane and the liquid-liquid equilibrium for TEG- $n$-heptane systems. As reported by Breil and Kontogeorgis [38], the argument for including these two binary systems in the pure component parameter estimation is that the description of the two binary systems is not acceptable when they are excluded. The binary interaction parameters for TEG-methane and TEG- $n$-heptane were estimated simultaneously with the pure component parameters. The parameter set 1 presents the lower deviations from vapor pressure data obtained from the DIPPR correlation (13\%) [40]. The other two sets present relatively higher deviations (up to $50 \%$ as shown in Table 7 ). More details are presented by Breil and Kontogeorgis [38] and will not be reproduced here.

Table 6. Pure fluid parameters for TEG.

\begin{tabular}{|l|l|l|l|l|l|l|l|}
\hline Fluid & $\boldsymbol{T}_{\boldsymbol{c}}(\mathbf{K})$ & $\begin{array}{l}\boldsymbol{b} \\
(\mathbf{L} / \mathbf{m o l})\end{array}$ & $\begin{array}{l}\boldsymbol{a}_{0} / \mathbf{R} \boldsymbol{b} \\
(\mathbf{K})\end{array}$ & $\mathbf{c}_{\mathbf{1}}$ & $\begin{array}{l}\boldsymbol{\varepsilon} / \boldsymbol{R} \\
(\mathbf{K})\end{array}$ & $\boldsymbol{\beta}$ & $\begin{array}{l}\text { Association } \\
\text { Scheme }\end{array}$ \\
\hline set 1 & 769.5 & 0.1321 & 3562.481 & 1.1692 & 1724.441 & 0.0188 & $4 \mathrm{C}$ \\
\hline set 2 & 769.5 & 0.128926 & 3622.490 & 0.9676 & 1697.13 & 0.0198 & $4 \mathrm{C}$ \\
\hline set 3 & 769.5 & 0.128926 & 3622.490 & 0.9100 & 1420.00 & 0.0200 & $6 \mathrm{D}$ \\
\hline set 4 new & 769.5 & 0.128663 & 3821.290 & 0.9791 & 1697.13 & 0.0198 & $4 \mathrm{C}$ \\
\hline & & & & & & & \\
\hline
\end{tabular}

Table 7. \%AAD of CPA correlations form vapor pressure and liquid density data (see figures 1-3 from Breil and Kontogeorgis [38])

\begin{tabular}{|l|l|l|l|}
\hline & $\% \mathrm{AAD}^{\mathrm{a}}$ in $\mathrm{P}^{\text {sat }}$ & $\% \mathrm{AAD}^{\mathrm{a}}$ in $\mathrm{P}^{\text {sat }}$ & $\% \mathrm{AAD}^{\mathrm{a}}$ in $\mathrm{V}^{\text {sat }}$ \\
\hline & $\begin{array}{l}0.5-0.8 \mathrm{Tc} \\
\text { (experimental, accepted } \\
\text { by DIPPR) }\end{array}$ & $\begin{array}{l}0.37-0.8 \mathrm{Tc} \\
\text { (experimental, accepted }+ \\
\text { rejected by DIPPR) }\end{array}$ & $\begin{array}{l}0.35-0.87 \mathrm{Tc} \\
\text { (DIPPR) }\end{array}$ \\
\hline set 1 & 5.3 & 12.6 & 3.1 \\
\hline set 2 & 52.3 & 52.9 & 2.5 \\
\hline set 3 & 33.0 & 39.4 & 3.1 \\
\hline set 4 new & 11.1 & 14.4 & 2.8 \\
\hline
\end{tabular}

${ }^{\mathrm{a}} \mathrm{AAD}$ as defined in the footnote of Table 1 
Based on the pure fluid parameter sets of Table 6, the phase behavior and other thermodynamic properties (such as heats of mixing) for some systems were investigated (mixtures of TEG with water, aromatic and aliphatic hydrocarbons). For TEG - water, the authors used experimental data for activity coefficients (333 K [41]), activity coefficients at infinite dilution (300 - $378 \mathrm{~K}$, [42]) and excess enthalpies (298 K, [43]). The obtained binary parameters that were found to describe in an acceptable way most data sets are presented in Table 8, while the model description is illustrated in Figures 7a-7e.

Table 8. Binary parameters for TEG - water [Breil and Kontogeorgis, 38].

\begin{tabular}{|l|l|l|}
\hline & $k_{i j}$ & $\beta_{\text {cross }}$ \\
\hline Set 1 & -0.201 & CR-1 \\
\hline Set 2 & $-0.10-40 / \mathrm{T}(\mathrm{K})$ & CR-1 \\
\hline Set 3 & $-0.05-39 / \mathrm{T}(\mathrm{K})$ & CR-1 \\
\hline
\end{tabular}

VLE data from Figure 7c [44], are relatively new and were not included by Breil and Kontogeorgis [38] in the parameter estimation. However, the parameter sets 1 and 2 describe the experimental data in a rather satisfactory way at lower temperatures. As shown in Figure $7 d$, only the parameter sets 2 and 3 accurately describe the excess enthalpies. However, all the parameter sets fail to describe the activity coefficients at infinite dilution (Figure 7e). 


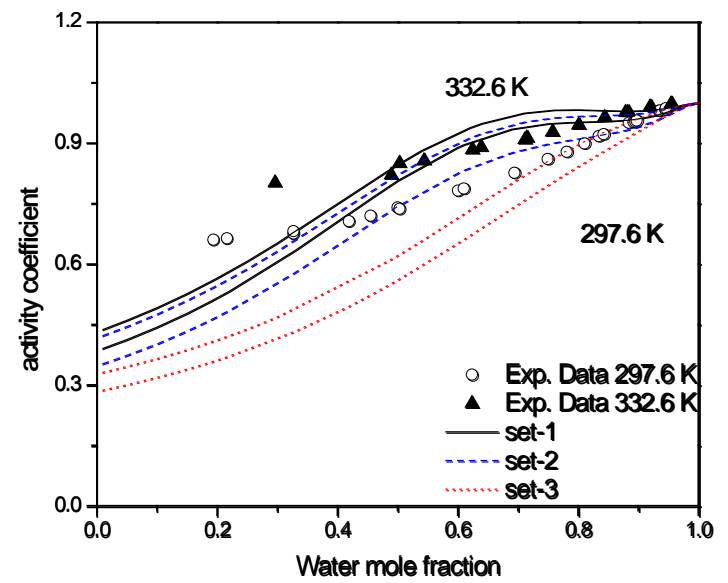

(a)

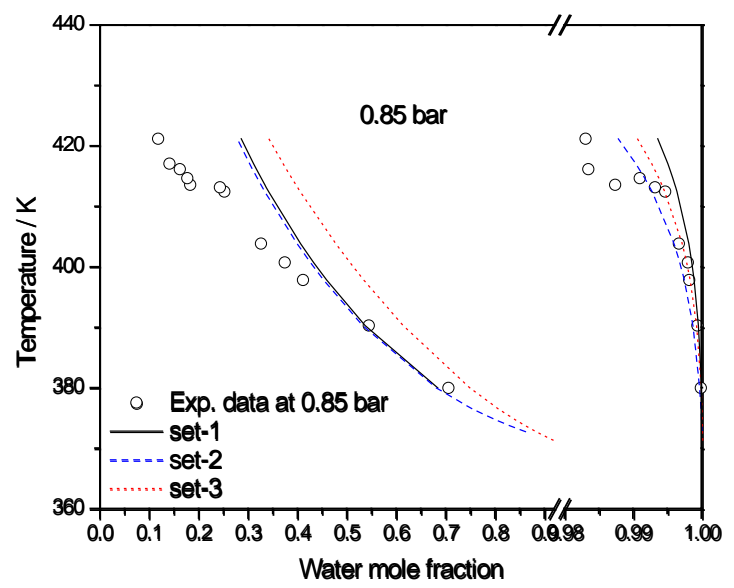

(c)

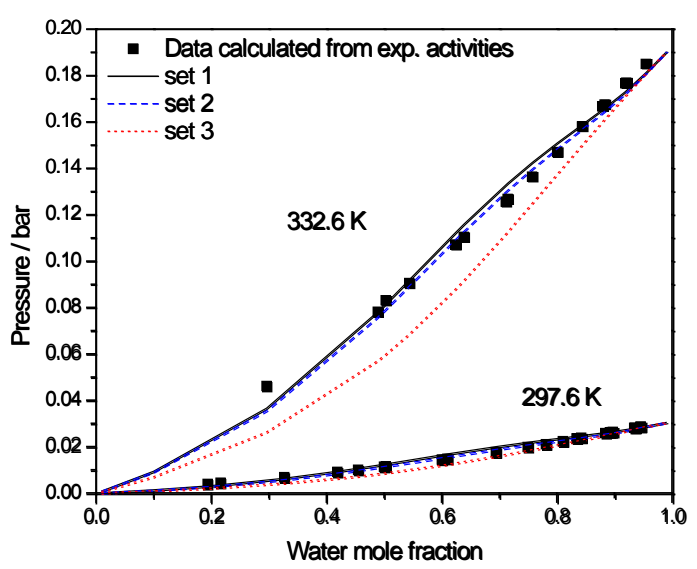

(b)

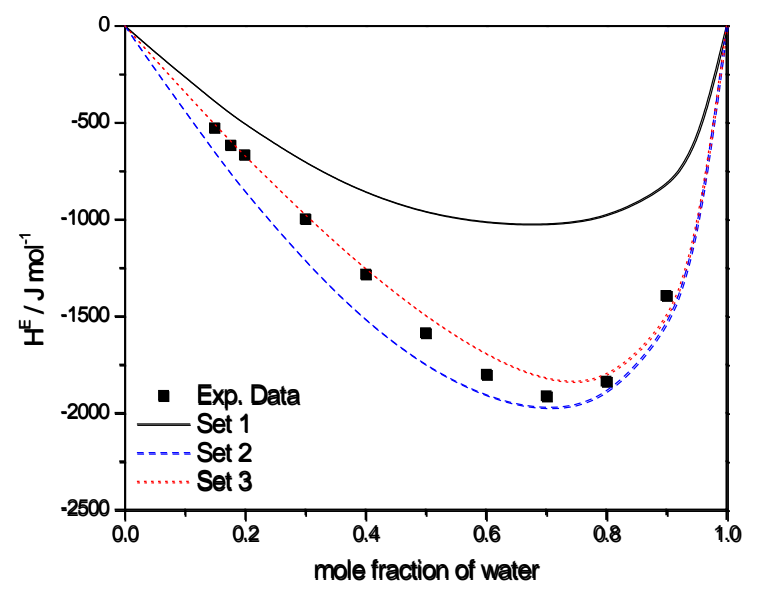

(d)

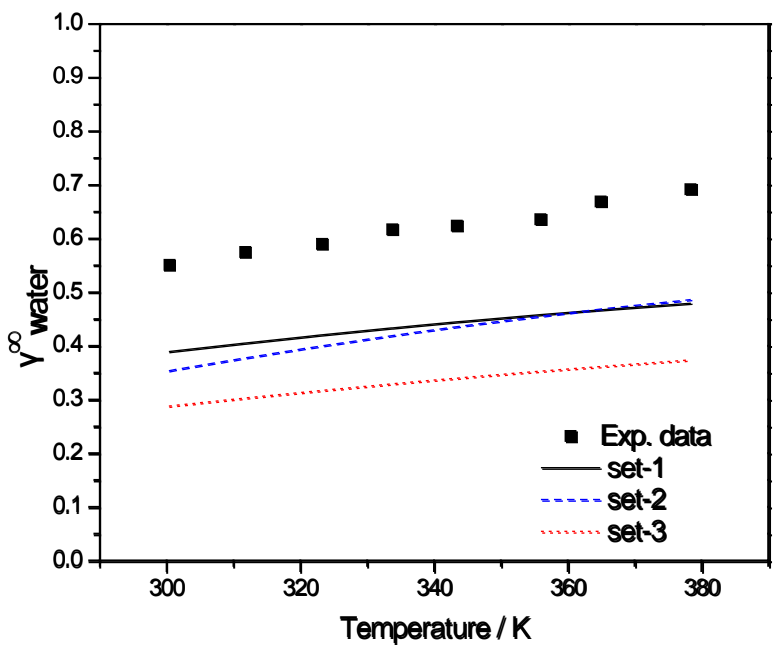

(e)

Figure 7. Thermodynamic properties of the TEG - water binary mixture. Experimental data (points) and CPA description (lines) with parameters from Tables 6 and 8. Activity coefficients (a), Mixture pressures calculated from activity coefficients (b), Vapor - liquid equilibrium (c), Excess enthalpies (d) and Activity coefficients at infinite dilution (e). 
The experimental data for the activity coefficients at infinite dilution, which are shown in Figure 7e and which were used by Breil and Kontogeorgis [38], were obtained from Parrish et al. [42]. Bestani and Shing [45] also measured the activity coefficients of water in TEG at infinite dilution. They report that their data points are around $15 \%$ higher than the data points of Parrish et al. [42]. According to the authors, this is due to the way that Parrish et al. interpreted their measurements. However, the accuracy of the data of Bestani and Shing were questioned in other literature studies. Twu et al. [46] mention that based on the Bestani and Shing extrapolation method to $477.15 \mathrm{~K}$, the predicted water activity coefficient is above 1.0. A value of water activity coefficient that is greater than unity at $477.15 \mathrm{~K}$ implies that TEG would be a poor dehydrating agent at around this temperature, which is contrary to plant experience. Therefore, they disregarded the data of Bestani and Shing [45] and used only the data of Parrish et al. [42].

\subsection{New pure component and mixture parameters}

In the study of Breil and Kontogeorgis [38], experimental vapor pressures of TEG for low temperatures (up to $343 \mathrm{~K}$ ) were not included in the parameter estimation. Such experimental data were rejected by DIPPR [40], when evaluating the data. For comparison reasons only, such low pressure data (of the order of $1 \mathrm{~Pa}$ ), were included in this study and another set (parameter set 4 of Table 6) was estimated. Then the binary parameters for TEG-water were estimated again, by including in the experimental data set all the data shown in Figures $7 \mathrm{a}$, 7c-7e. The results are shown in Tables 7 and 9.

Table 9. Binary parameters for TEG - water.

\begin{tabular}{|l|l|l|l|l|}
\hline & Set 1 & Set 2 & Set 3 & new Set 4 \\
\hline$k_{i j}$ & $0.0606-60.23 / T(\mathrm{~K})$ & $0.0733-67.04 / T(\mathrm{~K})$ & $0.2932-101.14 / T(\mathrm{~K})$ & $0.0674-63.04 / T(\mathrm{~K})$ \\
\hline$\beta_{\text {cross }}$ & CR1 & CR1 & CR1 & CR1 \\
\hline \%AAD in $P$ & 22.5 & 22.2 & 24.2 & 22.0 \\
\hline \%AAD in $y_{\text {TEG }}$ & 27.5 & 52.4 & 33.1 & 17.4 \\
\hline \%AAD in $\gamma$ & 19.0 & 18.5 & 16.5 & 18.0 \\
\hline \%AAD in $\gamma^{\infty}$ & 2.5 & 2.5 & 1.7 & 2.2 \\
\hline \%AAD in $H^{E}$ & 7.8 & 8.2 & 2.7 & 8.1 \\
\hline
\end{tabular}




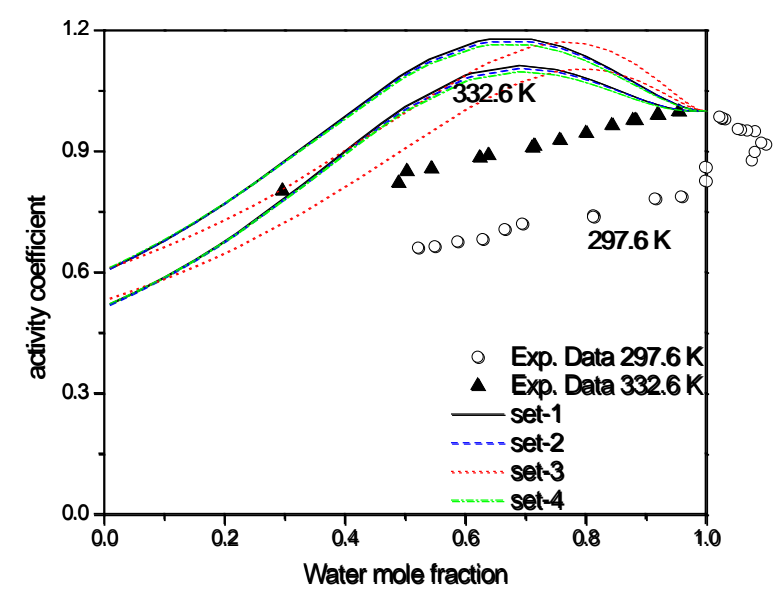

(a)

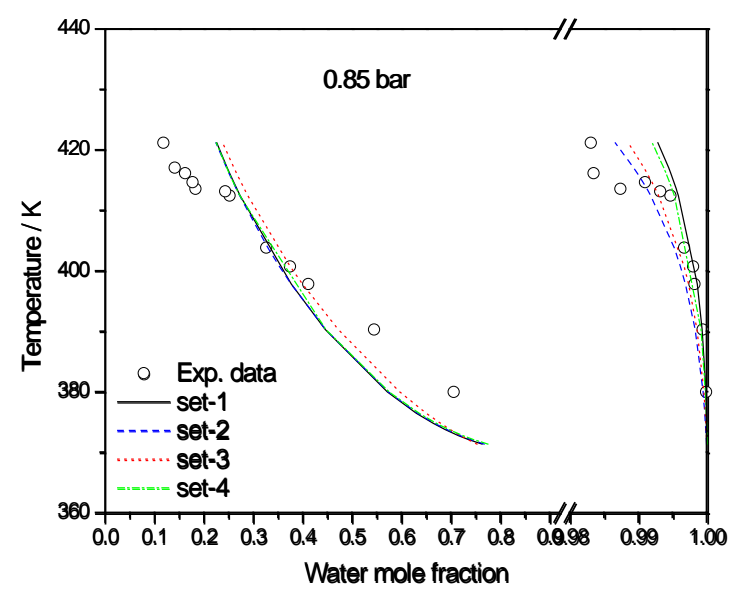

(c)

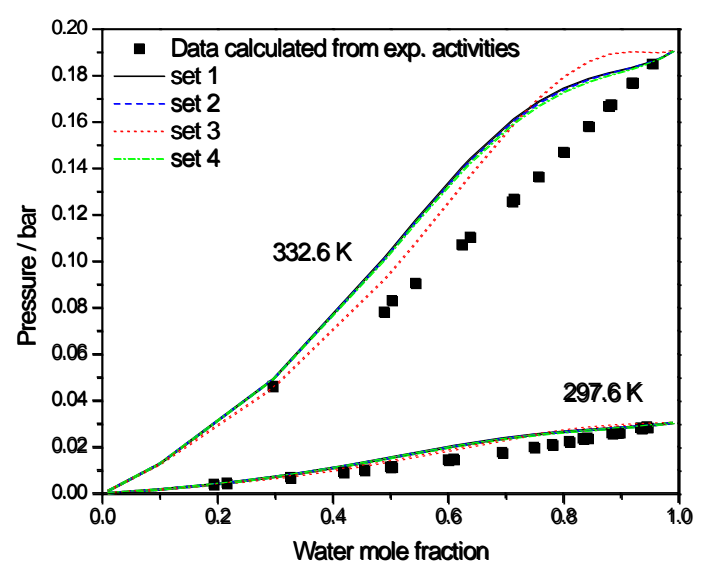

(b)

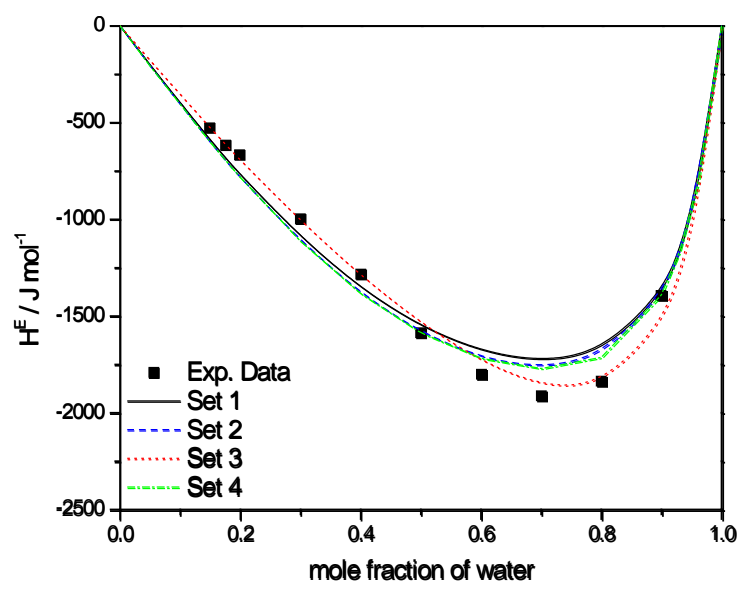

(d)

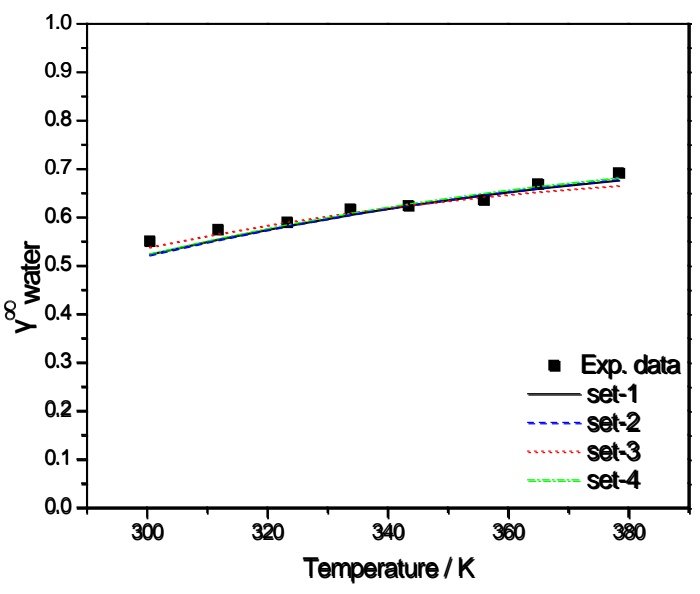

(e)

Figure 8. Thermodynamic properties of the TEG - water binary mixture. Experimental data (points) and CPA description (lines) with parameters from Tables 6 and 9. Activity coefficients (a), Mixture pressures calculated from activity coefficients (b), Vapor liquid equilibrium (c), Excess enthalpies (d) and Activity coefficients at infinite dilution (e). 
All the results are illustrated in Figure 8 and it can be concluded that all data sets accurately describe the excess enthalpies and the activity coefficients at infinite dilution. Furthermore, the VLE data of Figure 8c is rather satisfactorily described considering the uncertainty of the experimental data. However, from Figure 8a it is clear that the activity coefficients of water are not accurately described. A comparison of Figures 7 and 8 reveals that it is very difficult to obtain a temperature dependent $k_{i j}$ that can be used to accurately describe all the experimental data sets. The fitting procedure revealed that when the activity coefficients (data for relatively high water content mixtures) are accurately described, the deviation of model predictions form the experimental infinite dilution activity coefficient data increases and vice versa. Consequently, another approach was adopted, and it is shown next.

\subsection{Interaction parameters using also the cross association concept ( $\left.\boldsymbol{\beta}_{\text {cross }}\right)$}

The aforementioned difficulty is likely to originate from a poor representation of the cross association interactions between water and TEG, which were described using the CR-1 rule. Consequently, the CR-1 rule was abandoned for the cross association volume and the fitting procedure was repeated using three adjustable parameters: two parameters for the temperature dependency of the $k_{i j}\left(k_{i j}=a+b / T\right)$ and the cross association $\beta_{\text {cross }}$ parameter. The results are shown in Table 10 and are illustrated in Figure 9.

Table 10. Binary parameters for TEG - water.

\begin{tabular}{|l|l|l|l|l|}
\hline & Set 1 & Set 2 & Set 3 & new Set 4 \\
\hline$k_{i j}$ & $-0.1911-18.40 / T(\mathrm{~K})$ & $-0.1564-28.26 / T(\mathrm{~K})$ & $0.02617-58.13 / T(\mathrm{~K})$ & $-0.1755-22.27 / T(\mathrm{~K})$ \\
\hline$\varepsilon_{\text {cross }}$ & CR-1 & CR-1 & CR-1 & CR-1 \\
\hline$\beta_{\text {cross }}$ & 0.0305 & 0.0320 & 0.0310 & 0.0315 \\
\hline \%AAD in $P$ & 16.5 & 16.3 & 18.6 & 16.2 \\
\hline \%AAD in $y_{T E G}$ & 25.6 & 55.7 & 39.3 & 17.2 \\
\hline \%AAD in $\gamma$ & 3.9 & 4.4 & 2.0 & 3.9 \\
\hline \%AAD in $\gamma^{\infty}$ & 1.6 & 1.7 & 1.7 & 2.1 \\
\hline \%AAD in $H^{E}$ & 3.4 & 3.9 & 4.7 & 3.5 \\
\hline
\end{tabular}




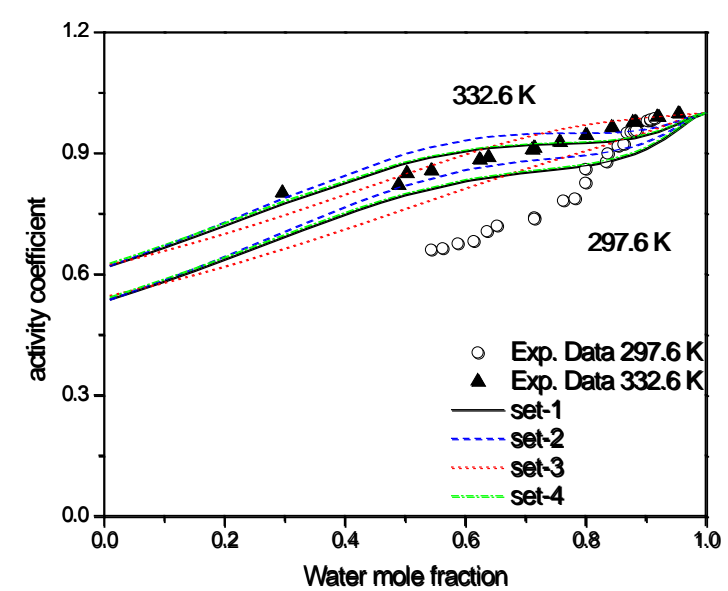

(a)

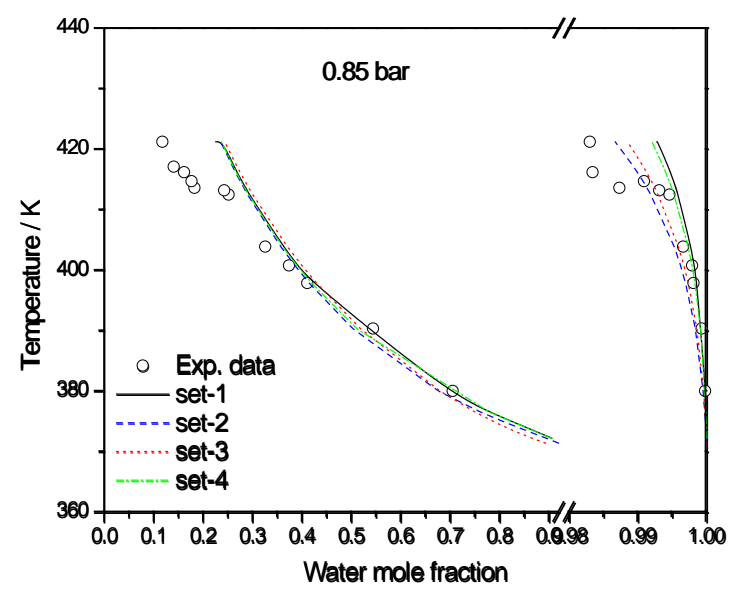

(c)

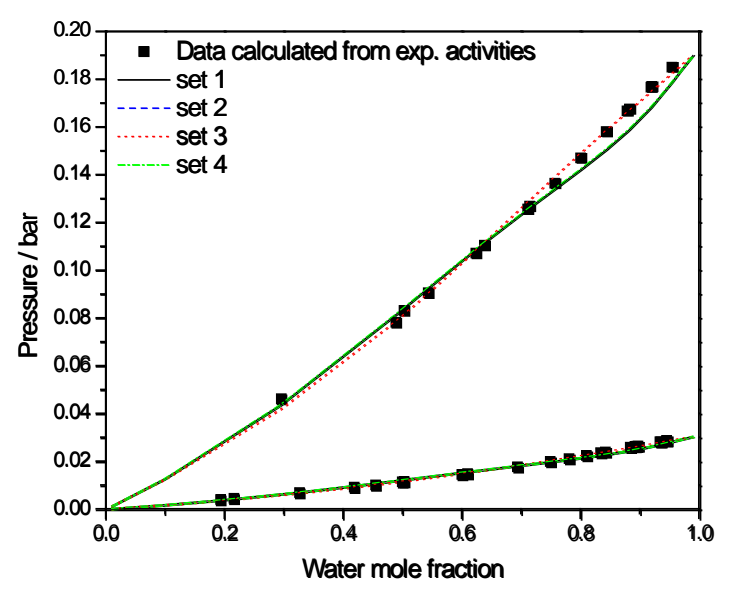

(b)

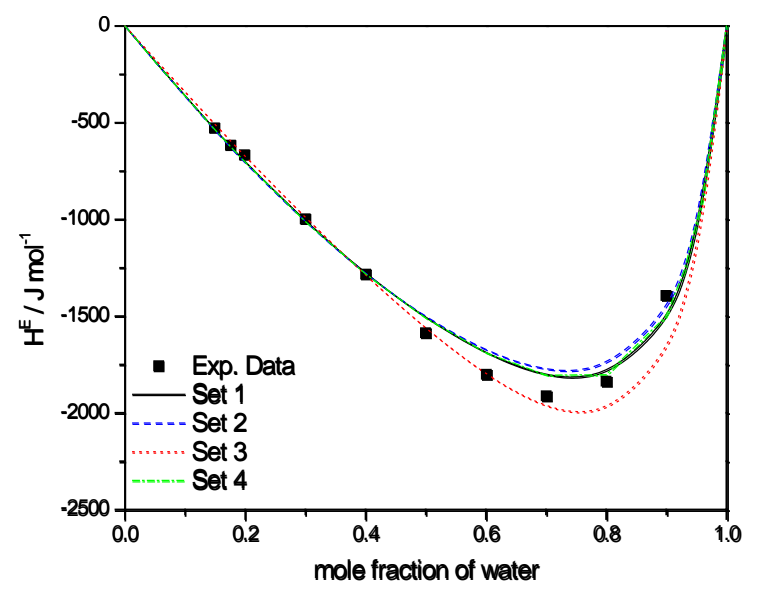

(d)

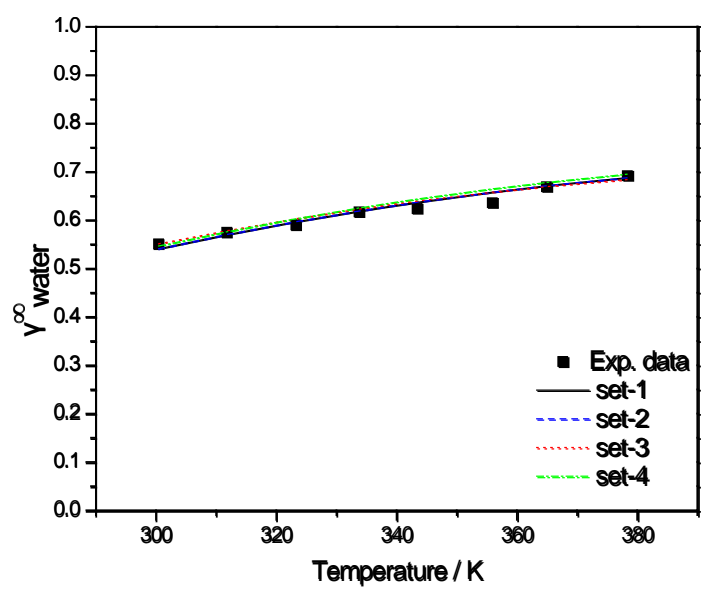

(e)

Figure 9. Thermodynamic properties of the TEG - water binary mixture. Experimental data (points) and CPA description (lines) with parameters from Tables 6 and 10. Activity coefficients (a), Mixture pressures calculated from activity coefficients (b), Vapor liquid equilibrium (c), Excess enthalpies (d) and Activity coefficients at infinite dilution (e). 
As shown in Table 10, deviations from experimental data are different for the various parameter sets. However, considering also the uncertainty of some experimental data sets (see for example Figures 9a and 9c), it is difficult to choose the best parameter set. Using three adjustable parameters all the used experimental data sets seem to be satisfactorily described. However, set 1 more accurately describes the pure TEG vapor pressures, while sets 2 and 3 the mixtures with hydrocarbons (see Breil and Kontogeorgis [38]). Moreover, in mixtures with water the new binary parameters of Table 10 yield better calculations for some properties (such as activity coefficients at infinite dilution for example).

Finally, using the binary parameters of Table 10, the model was applied to predict the SLE of the TEG-water system. In this direction, the temperature dependent kij values of Table 10 were extrapolated to low temperatures (232 - 273K), lower than the temperature range at which they were regressed ( $297-420 \mathrm{~K}$ ). SLE calculations were performed using the values for the fusion properties of the compounds that are shown in Table 11.

Table 11. Fusion properties of water and TEG [40,47].

\begin{tabular}{lll}
\hline Fluid & $\mathbf{T}_{\mathbf{m}} \mathbf{( K )}$ & $\mathbf{\Delta} \mathbf{H}_{\mathbf{f}} \mathbf{( \mathbf { J ~ } ~ \mathbf { ~ m o l } ^ { - \mathbf { 1 } } )}$ \\
\hline Water & 273.15 & 6001.74 \\
TEG & 268.85 & 18200 \\
\hline
\end{tabular}

The experimental data for water and TEG were found in various sources [48-51]. All the collected experimental data and the predictions of the model using the various pure and binary parameters are presented in Figure 10 and Table 12. From the results, it is concluded that the model satisfactorily predicts the SLE in all cases. Considering the differences between the various experimental data sets, no safe conclusion can be made for the best parameter set for SLE calculations. However, it can be speculated that sets 2 and 3 perform better than the others.

Table 12. \% AAD in the composition of the liquid phase for the SLE of water - TEG system

\begin{tabular}{|l|l|l|}
\hline & $\begin{array}{l}\text { \% AAD in } \mathrm{x}_{\text {water }} \\
\text { (in Solid water }- \text { Liquid 1 SLE) }\end{array}$ & $\begin{array}{l}\text { \% AAD in } \mathrm{x}_{\text {TEG }} \\
\text { (in Solid TEG - Liquid 2 SLE) }\end{array}$ \\
\hline Set 1 & 1.5 & 14.5 \\
\hline Set 2 & 1.0 & 14.9 \\
\hline Set 3 & 0.8 & 13.6 \\
\hline Set 4 & 1.3 & 14.5 \\
\hline
\end{tabular}




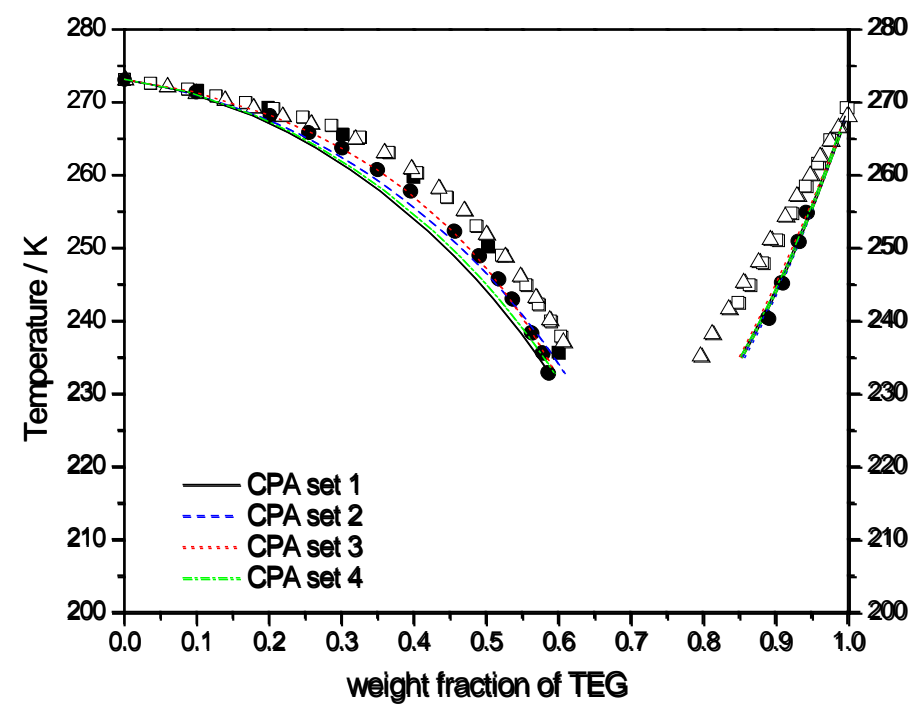

Figure 10. Water - TEG SLE. Experimental data (points) [48-51] and CPA predictions (lines).

\subsection{Need for a more advanced approach ?}

Since TEG contains both hydroxyls $(-\mathrm{OH})$ and ether oxygens $(-\mathrm{O}-)$, which can act as hydrogen bonding sites, another association approach was tested in order to investigate whether improved performance can be obtained. According to this approach, one proton donor and one proton acceptor sites were assumed on every - $\mathrm{OH}$ group, while one proton acceptor site was assumed on every $-\mathrm{O}-$ group. The $-\mathrm{OH}$... OH- interaction parameters were adopted from ethanol ( $\varepsilon^{A i B j} / R=2586.8 \mathrm{~K}$ and $\left.\beta^{A i B j}=0.0080\right)$, while the $-\mathrm{OH}$...-O-O- interaction parameters were adopted from ethanol - dimethyl ether binary mixture $\left(\varepsilon^{A i B j} / R=1294.924 \mathrm{~K}\right.$ and $\beta^{A i B j}=0.5007$ [52]. The remaining pure fluid parameters were adjusted to vapor pressure and liquid density data. All the pure fluid parameters for TEG are reported in Table 13.

In mixtures with water, the $\mathrm{HOH} . . . \mathrm{HO}$ - interaction parameters were estimated using the CR-1 rule. Furthermore, the $\mathrm{HOH}$....-O- interaction parameters were adopted from the water - dimethyl ether binary mixture $\left(\varepsilon_{\text {cross }} / R=1001.6 \mathrm{~K}\right.$ and $\beta_{\text {cross }}=0.3832$ [52]. The results for the binary water - TEG mixture using this approach are reported in Table 14. The comparison of Table 14 with Tables 9 and 10, reveals that this approach does not yield better results. A possible reason for that is the use of the combining rule for estimating the HOH...HOinteraction parameters. Although this approach results in successful correlations for wateralcohol mixtures, it is still an approach without a strong physical base.

Table 13. Pure fluid parameters for TEG.

\begin{tabular}{|l|l|l|l|l|l|l|}
\hline $\boldsymbol{T}_{\boldsymbol{c}}(\mathbf{K})$ & $\begin{array}{l}\boldsymbol{b} \\
(\mathbf{L} / \mathbf{m o l})\end{array}$ & $\begin{array}{l}\boldsymbol{a}_{0} / \boldsymbol{R} \boldsymbol{b} \\
(\mathbf{K})\end{array}$ & $\mathbf{c}_{\mathbf{1}}$ & $\begin{array}{l}\boldsymbol{\varepsilon} / \boldsymbol{R} \\
(\mathbf{K})\end{array}$ & $\boldsymbol{\beta}$ & interaction \\
\hline 769.5 & 0.1321 & 3562.481 & 1.1692 & 2586.8 & 0.0080 & $-\mathrm{OH} . . \mathrm{OH}-$ \\
\hline & & & & 1294.9 & 0.5007 & $-\mathrm{OH} . . . \mathrm{O}-$ \\
\hline
\end{tabular}


Table 14. Binary parameters for TEG - water.

\begin{tabular}{|l|l|}
\hline & New approach \\
\hline$k_{i j}$ & $0.378287-112.544 / T(\mathrm{~K})$ \\
\hline \%AAD in $P$ & 29.2 \\
\hline \%AAD in $y_{T E G}$ & 30.0 \\
\hline \%AAD in $\gamma$ & 30.8 \\
\hline \%AAD in $\gamma^{\infty}$ & 3.2 \\
\hline \%AAD in $H^{E}$ & 8.12 \\
\hline
\end{tabular}

\subsection{Prediction of multicomponent phase equilibria (water - TEG - methanol - hydrocarbon)}

Subsequently, CPA was applied to predict the phase behavior of a multicomponent system that contains water, TEG, methanol, propane and methane using two pure fluid parameter sets for TEG (sets 1 and 2 of Table 6). Pure fluid parameters for the remaining fluids were adopted from Arya et al. [53] and Tsivintzelis and Kontogeorgis [52]. The experimental data were adopted from $\mathrm{Ng}$ and Schroeder [54] who report the feed compositions of initial unstable mixtures and the equilibrium compositions of vapor and liquid phases. Consequently, flash calculations were performed, while all the reported data were considered. In all cases the required binary parameters were adopted from the corresponding sub-binary systems and are presented in Table 15. No parameters were adjusted to the multicomponent system data. The deviations of CPA predictions from the experimental data are presented in Table 16, while some characteristic calculations for the $283.15 \mathrm{~K}$ data are presented in Figure 11 and Figures S2-S6 of the supporting information file.

Table 15. CPA binary parameters.

\begin{tabular}{|l|l|l|l|}
\hline Sub-binary system & $\boldsymbol{k}_{\boldsymbol{i j}}$ & $\boldsymbol{\beta}_{\text {cross }}$ & Ref. \\
\hline Water - TEG (set1) & $-0.1911-18.40 / T(\mathrm{~K})$ & 0.0305 & {$[53]$} \\
\hline Water - TEG (set2) & $-0.1564-28.26 / T(\mathrm{~K})$ & 0.0320 & This work \\
\hline & & & \\
\hline Water - Methanol & -0.0748 & (CR-1) & This work \\
\hline TEG (set1) - Methanol & 0 & (CR-1) & \\
\hline TEG (set2) - Methanol & 0 & (CR-1) & \\
\hline & & & \\
\hline Water - $\mathrm{CH}_{4}$ & $0.7988-236.5 / T(K)$ & & {$[53]$} \\
\hline TEG (set1) - $\mathrm{CH}_{4}$ & $0.14933+4.92 / T(K)$ & & {$[53]$} \\
\hline TEG (set2) - $\mathrm{CH}_{4}$ & $0.13574+20.27 / T(K)$ & & {$[53]$} \\
\hline Methanol - CH $\mathrm{CH}_{4}$ & 0.0528 & & {$[35]$} \\
\hline & & & \\
\hline Water - Propane & $0.4809-130.5 / T(K)$ & & {$[53]$} \\
\hline TEG (set1) - Propane & 0.1235 & & This work \\
\hline TEG (set2) - Propane & 0.1420 & & This work \\
\hline Methanol - Propane & $0.1311-22.562 / T(\mathrm{~K})$ & & {$[55]$} \\
\hline CH ${ }_{4}-$ Propane & 0 & & \\
\hline
\end{tabular}


Table 16. Percentage Average Absolute Deviations of CPA predictions from the experimental data (VLE of the water (1) - TEG (2) - methanol (3) - methane (4) - propane (5) system).

\begin{tabular}{|l|l|l|l|l|l|l|l|l|l|l|l|}
\hline & & \multicolumn{9}{|c|}{ \% AAD in } \\
\hline & $\mathbf{T} / \mathbf{K}$ & $\mathbf{x}_{\mathbf{1}}$ & $\mathbf{x}_{\mathbf{2}}$ & $\mathbf{x}_{\mathbf{3}}$ & $\mathbf{x}_{\mathbf{4}}$ & $\mathbf{x}_{\mathbf{5}}$ & $\mathbf{y}_{\mathbf{1}}$ & $\mathbf{y}_{\mathbf{3}}$ & $\mathbf{y}_{\mathbf{4}}$ & $\mathbf{y}_{\mathbf{5}}$ \\
\hline set 1 & 283.15 & 1.8 & 1.1 & 1.9 & 18.8 & 7.7 & 54.6 & 21.1 & 0.2 & 5.2 \\
\hline set 2 & 283.15 & 1.7 & 1.0 & 1.7 & 14.4 & 5.5 & 54.3 & 19.9 & 0.2 & 5.3 \\
\hline & & & & & & & & & & \\
\hline set 1 & 299.82 & 4.6 & 1.4 & 4.6 & 19.9 & 53.7 & 42.8 & 14.0 & 0.1 & 2.7 \\
\hline set 2 & & 4.5 & 1.4 & 4.5 & 17.1 & 52.5 & 40.7 & 13.2 & 0.1 & 2.5 \\
\hline & & & & & & & & & & \\
\hline set 1 & 322.04 & 8.8 & 2.3 & 8.8 & 17.4 & 9.8 & 60.8 & 23.1 & 0.1 & 2.9 \\
\hline set 2 & 322.04 & 8.8 & 2.4 & 8.7 & 16.3 & 8.0 & 60.0 & 23.4 & 0.1 & 2.7 \\
\hline & & & & & & & & & & \\
\hline set 1 & 338.71 & $<0.1$ & $<0.1$ & 0.1 & 17.3 & 11.9 & 30.1 & 6.0 & 0.7 & 3.9 \\
\hline set 2 & 338.71 & $<0.1$ & $<0.1$ & $<0.1$ & 17.1 & 8.8 & 25.9 & 5.4 & 0.6 & 3.8 \\
\hline & & & & & & & & & & \\
\hline total & set 1 & 3.8 & 1.2 & 3.8 & 18.3 & 20.8 & 47.1 & 16.0 & 0.3 & 3.7 \\
\hline & set 2 & 3.8 & 1.2 & 3.8 & 16.2 & 18.7 & 45.2 & 15.5 & 0.3 & 3.6 \\
\hline
\end{tabular}

As shown in Table 16, both sets satisfactorily predict the compositions of both phases. However, it seems that that the pure fluid parameter set-2 coupled with the binary parameters of Table 15 presents lower deviations for the methane and propane content of the liquid phase and the water content of the vapor phase. Here it is worth mentioning that experimental data for the TEG content of the vapor phase are not reported, probably due to the very low concentrations. The TEG content of the vapor phase could be a better benchmark for evaluating the TEG pure fluid parameter sets.

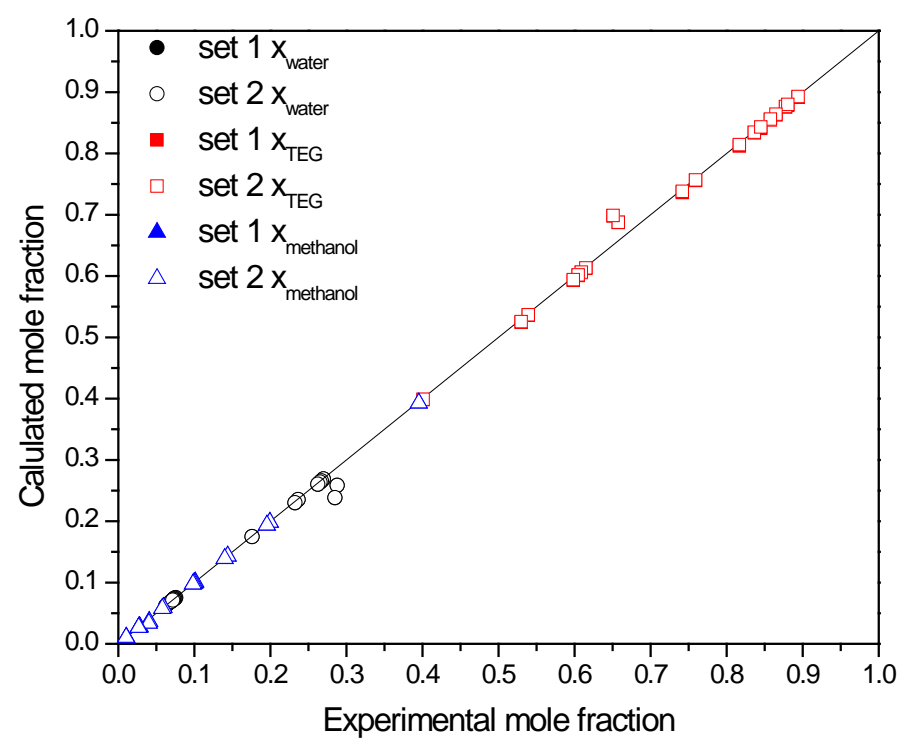

Figure 11. Calculated vs experimental liquid phase composition for the VLE of the water - TEG methanol - methane - propane system (mole fractions of water, TEG, methanol). 


\subsection{Concluding remarks}

A deeper study of the modeling of the industrially important TEG-water system has been carried out using CPA parameters from literature (Breil and Kontogeorgis, [38]) and new parameters (pure TEG and mixtures with water). The emphasis of this exercise is to try to represent a very wide range of experimental data and conditions including activity coefficients at infinite dilution. It was concluded that the pure fluid parameter sets 2 and 3, estimated by Breil and Kontogeorgis [38], could continue to be used for TEG. However, it was also found that this binary mixture is accurately described using a temperature dependent binary interaction parameter and a value for the cross association volume adjusted to the binary experimental data.

CPA calculations for the vapor - liquid equilibrium of the five-component water-TEGmethanol-methane-propane system were performed using two pure fluid parameter sets for TEG. In all cases, the binary parameters were adopted from the corresponding sub-binary mixtures and the model was used to predict the compositions of the phases in equilibrium. CPA successfully describes the phase behavior of this system, while the predictions with the two different parameter sets are very similar. However, set 2 seems to be more accurate for the liquid phase composition and especially for the methane and propane content as well as for the vapor phase content of water.

\section{Case study III: How much more "physics"? The case of quadrupolar molecules}

We saw in section 3, with the TEG-water case study, that "additional physics" i.e. introducing a more advanced association scheme for TEG and its interactions with water did not improve the representation of several properties of that mixture. This is a general issue. How many more "physical effects", how much "more theory" should be incorporated in association models and what is the appropriate balance between complexity and simplicity? An area which is much discussed in literature is whether polar and quadrupolar effects should be explicitly accounted for, as additional interactions, in association models. We consider here the case of qCPA (a quadrupolar version of CPA) which has been recently developed by Bjørner and Kontogeorgis [56,57], see also Bjørner et al. [58]. We present some unpublished results and, together with those from literature, we discuss the aforementioned questions. We have chosen to show exclusively results of $\mathrm{CO}_{2}$ with alkanes and other inert compounds, as considering mixtures with water and other polar compounds often "mask" the importance of quadrupolar interactions (in such polar $\mathrm{CO}_{2}$-containing mixtures association and crossassociation/solvation effects tend to be more important). Results for such polar mixtures are shown by Bjørner and Kontogeorgis [56,57]

\section{1 $\mathrm{CO}_{2}$-alkanes VLE and LLE}

As can be seen in figures $12 \mathrm{a}$ and $12 \mathrm{~b}$ and also as shown by Bjørner and Kontogeorgis [56,57], qCPA performs better than CPA in a predictive way (i.e using zero interaction parameters, $k_{i j}=0$ ) and thus it is possible to greatly improve the predicted phase behavior of the $\mathrm{CO}_{2}+n$-alkane mixtures by taking the quadrupole moment of $\mathrm{CO}_{2}$ into account. 
However, in order to accurately model both VLE and LLE for $\mathrm{CO}_{2}+n$-alkane series, all modeling approaches need a non-zero binary interaction parameter. A temperature independent interaction parameter is sufficient in all cases, as can be seen in figures 12b,c.

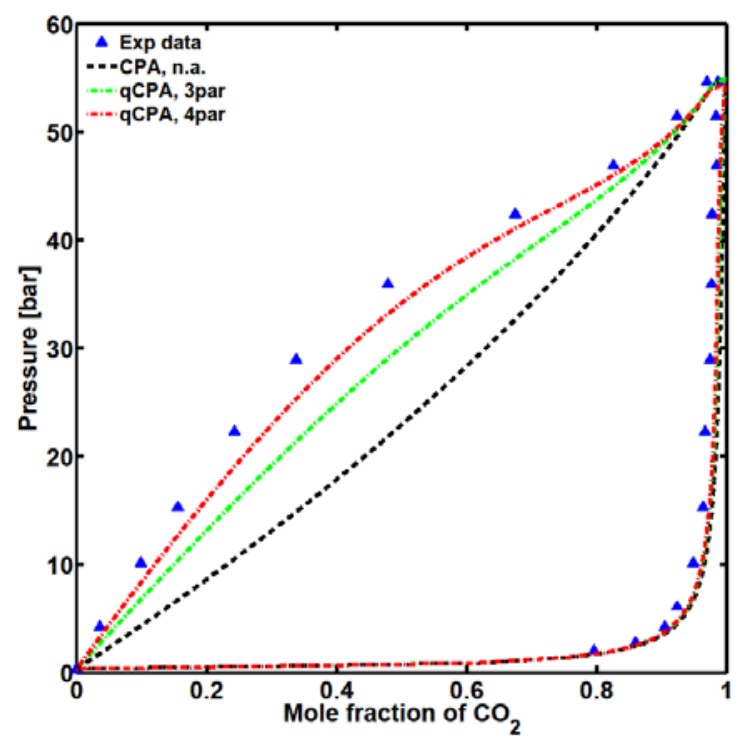

Figure 12a. Prediction $\left(k_{i j}=0\right)$ of the $\mathrm{CO}_{2}+$ cyclopentane VLE at $293 \mathrm{~K}$ using CPA where $\mathrm{CO}_{2}$ is treated as an inert non-associating compound (n.a.) and qCPA with either three or four adjustable parameters (3par, 4par). The predictions are compared with experimental data are from Ref. [59].

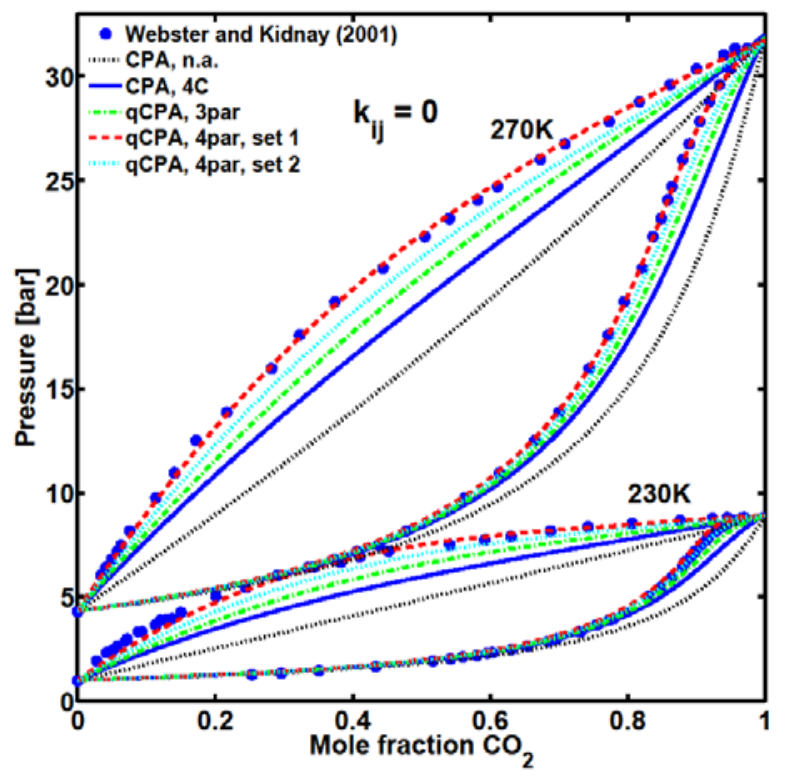

Figure 12b. Predictions $\left(k_{i j}=0\right)$ compared to experimental data for the $\mathrm{CO}_{2}+$ propane VLE at $270 \mathrm{~K}$ and $230 \mathrm{~K}$ using $\mathrm{CPA}$, where $\mathrm{CO}_{2}$ is treated either as a non-associating (n.a.) or self- 
associating compound (scheme 4C), and qCPA with either three or four parameters (with two parameter sets evaluated in the latter case). Experimental data are from Ref. [60].

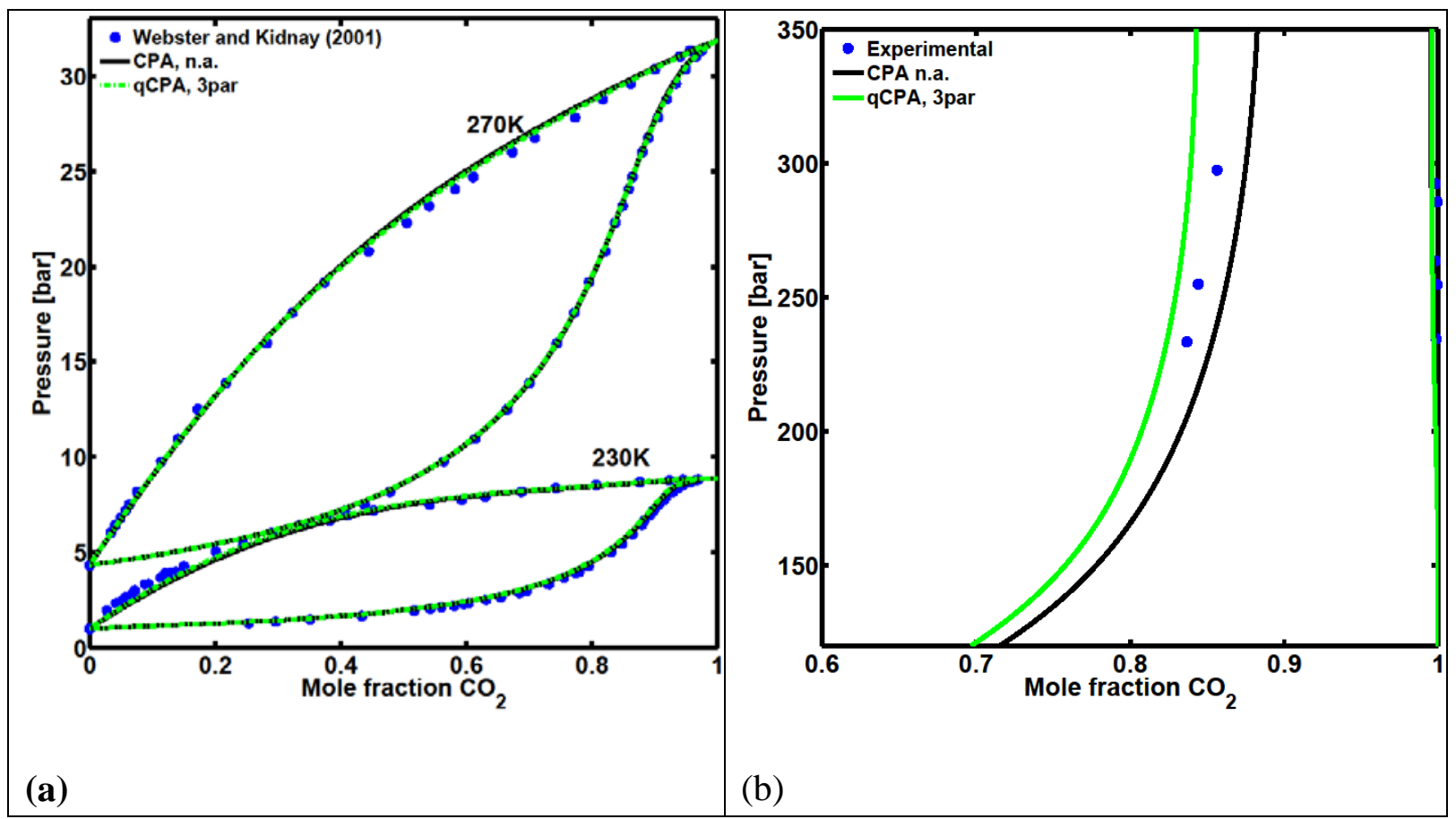

Figure 12c. VLE of (a) $\mathrm{CO}_{2}+$ propane and LLE of (b) $\mathrm{CO}_{2}+\mathrm{C}_{36}$ where the correlations shown in fig. 13 have been employed for qCPA with three parameters and non-associating CPA. Experimental data are from Refs. [60,61].

Generalized correlations for the binary interaction parameters are useful for extrapolationprediction purposes, but also for assessing the overall physical meaning of a thermodynamic model e.g. if such interaction parameters follow smooth trends against carbon chain length.

In figure 13 the interaction parameters of the binary $\mathrm{CO}_{2}+n$-alkane pairs are plotted as a function of the molecular weight of the $n$-alkane (from $\mathrm{C}_{2}-\mathrm{C}_{36}$ ). The vertical dashed line indicates the transition from VLE data (left-hand side) to LLE data (right-hand side). The figure shows the trend in $k_{i j}$ for qCPA with three parameters and for CPA without association. It is clear that there is a tendency for the interaction parameter to decrease as a function of the molecular weight (or carbon number) of the $n$-alkane with both approaches. The logarithmically decreasing function of the molecular weight of the hydrocarbon shown in figure 13 is in agreement with previous CPA studies for other families e.g. water-alkanes and MEG-alkanes.

The interaction parameters with the qCPA are significantly smaller and the decrease with molecular weight is somewhat slower, and this further supports why much better results are obtained with qCPA using $k_{i j}=0$ (predictive approach). 


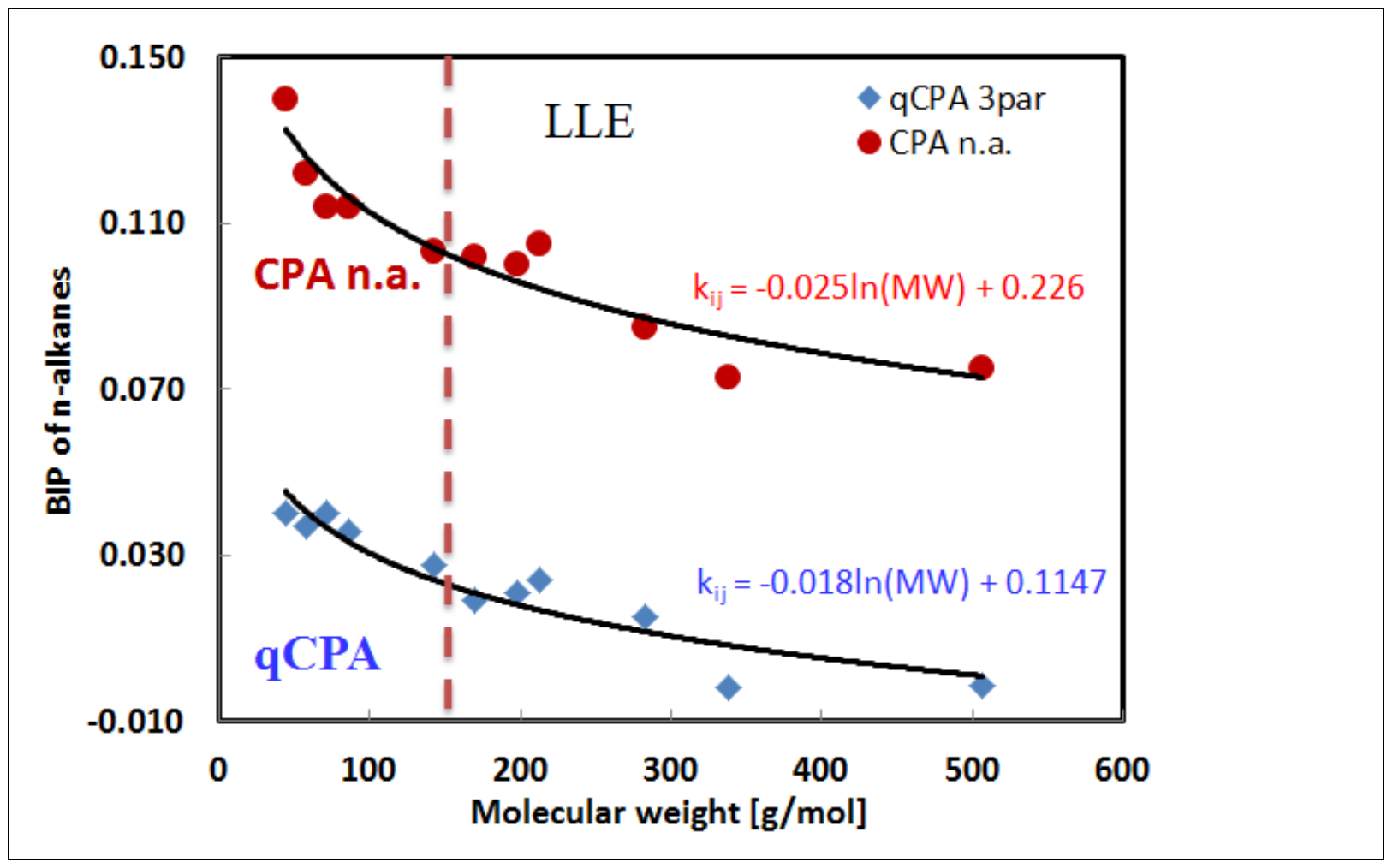

Figure 13. Binary interaction parameters for qCPA (with 3 adjustable parameters) and CPA without association for $\mathrm{CO}_{2}+\mathrm{n}$-alkane mixtures, as a function of the molecular weight of the n-alkane. Points are the correlated values for each subsystem and lines are correlations to the series behavior. The vertical dashed line indicates the transition from VLE to LLE.

As shown in figure 12c, for the VLE of $\mathrm{CO}_{2}+$ propane and LLE of $\mathrm{CO}_{2}$ + hexatriacontane $\left(\mathrm{C}_{36}\right)$, the correlations give quite satisfactory results for both models. As is typically the case, the LLE is more sensitive to the $k_{i j}$ value and the results with both qCPA and CPA are not quite as good as with an individually fitted $k_{i j}$, whereas results for the VLE are similar to the individual correlation.

\subsection{Excess enthalpies}

While a main purpose of an equation of state is to correlate and predict the phase equilibria between mixtures, other properties are also important in practical applications and from a theoretical or a modelling point of view they are also crucial in determining the applicability range and boundaries of a thermodynamic model. As seen in case study I, one such property is the excess enthalpy. 
Figure 14 shows the predicted $\left(k_{i j}=0\right)$ molar excess enthalpy of the $\mathrm{CO}_{2}+$ ethane mixture at $217 \mathrm{~K}$ and at saturation pressures. Figure 14b (right) illustrates the excess enthalpy of the mixture using binary interaction parameters correlated to binary VLE data. Both calculations shown in figures 14a,b are, thus, predictive in the sense that no binary parameters are directly correlated to the excess enthalpy. It should be, however, mentioned that in the latter calculation (figure 14b) binary interaction parameter is used, which is correlated to VLE data. Figure 14a (left) shows that all qCPA variants predict the excess enthalpy quite well and significantly better than when $\mathrm{CO}_{2}$ is modeled as a self-associating or inert compound. However, when binary interaction parameters correlated to VLE are employed (figure 14b), both CPA variants perform very well and better than qCPA, for which all approaches now over-predict the excess enthalpy.
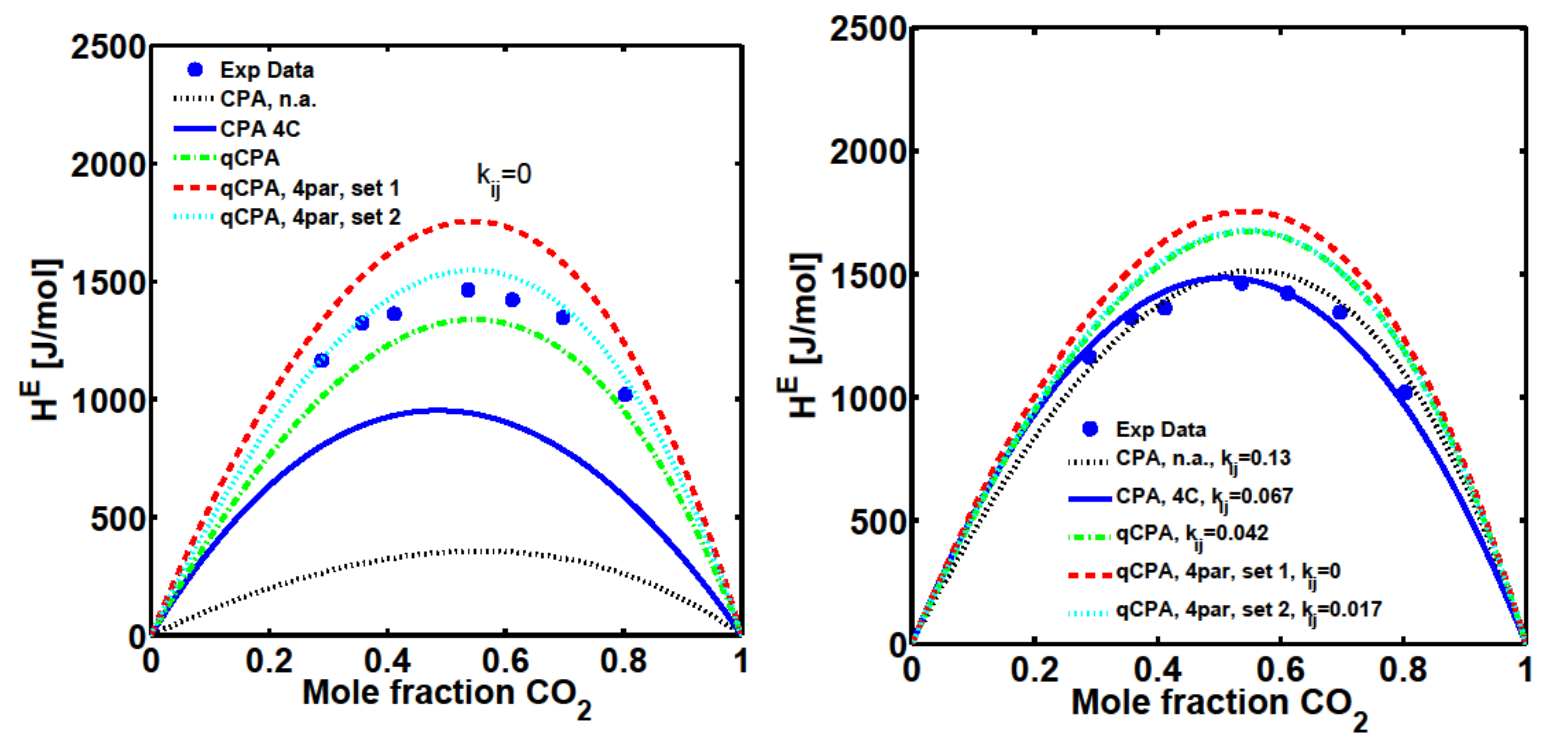

Figure 14. Excess enthalpy of the $\mathrm{CO}_{2}+$ ethane mixtures at $217 \mathrm{~K}$ and saturation pressure. The employed CPA modeling approaches are $\mathrm{CO}_{2}$ is treated either as a non-associating (n.a.) or self-associating compound (scheme 4C), or qCPA with either three or four parameters. (a) - left shows the predicted excess enthalpy with $k_{i j}=0$, and (b)-right shows the predicted excess enthalpy with the $k_{i j}$ values obtained from VLE data. Experimental data from Ref. [62].

\subsection{Multicomponent systems containing $\mathrm{CO}_{2}$ and $n$-alkanes}

For multicomponent mixtures containing only hydrocarbons the binary interaction parameters are close to zero and satisfactory predictions are typically obtained with CPA (or SRK). In this regard an interesting group of multicomponent systems are those containing $\mathrm{CO}_{2}$ and multiple n-alkanes. For these systems, dispersion and quadrupolar forces should essentially be the only interactions and there is no question as to how $\mathrm{CO}_{2}$ should be modeled in mixtures with associating compounds. We have considered four modelling approaches (using 
the numbering from the original publications, refs 56-58]; case A (CPA, inert $\mathrm{CO}_{2}, 3$ pure component parameters), case $\mathrm{C}$ (CPA with associating $\mathrm{CO}_{2}, 5$ pure component parameters), case $\mathrm{D}$ (qCPA with 3 adjustable parameters) and case $\mathrm{E}$ (qCPA with 4 adjustable parameters). In all cases $k_{i j}$ is adjusted from experimental data.

It is obvious from previous studies [56-58] that almost quantitative predictions $\left(k_{i j}=0\right)$ were obtained for binary mixtures containing $\mathrm{CO}_{2}$ and hydrocarbons when qCPA was employed with four parameters (case E). The predictions were also quite satisfactory when the model was employed with three parameters (case D). An important question is whether the excellent phase equilibrium results for binary mixtures are maintained to multicomponent mixtures.

To investigate this, the VLE of the mixtures $\mathrm{CO}_{2}+$ methane + ethane and $\mathrm{CO}_{2}+$ ethane $+\mathrm{n}$ eicosane are studied with qCPA and CPA. The binary interaction parameters between ethane + methane and ethane + eicosane are both assumed to be zero. Furthermore, the mixtures are studied both with and without a $k_{i j}$ between $\mathrm{CO}_{2}$ and the hydrocarbons.

The deviations between model predictions, both with and without interaction parameters, and experimental data are shown in Table 17 . When all $k_{i j}$ 's are set to zero no deviations are presented for case A, as VLEs are not predicted for all data points when the center of the experimental tie line is used as the feed composition.

The $\mathrm{CO}_{2}+$ methane + ethane system is a very interesting system, which depends strongly on pressure. At low pressures the bubble- and dew-point curves coincide, while at higher pressures the distance between the curves increases and then decreases again. The predictions were compared to experimental data from Wei et al. [63] at $230 \mathrm{~K}$ and 65 bar and Davalos et al. [64] at $250 \mathrm{~K}$ and three pressures (21, 25, and $30 \mathrm{bar})$. It is clear from Table 17 that case $\mathrm{E}$ performs very well without a $k_{i j}$, as all deviations between model predictions and experimental data are smaller than $10 \%$, with the exception of the composition of the liquid methane phase. The deviations with the different modeling approaches are almost identical when binary interaction parameters are employed (this is also illustrated in figure 15b). Interestingly, most deviations increase slightly when case $\mathrm{E}$ is employed with binary interaction parameters.

Figure 15 illustrates, in a ternary diagram, the VLE predictions of the $\mathrm{CO}_{2}+$ methane + ethane system at $250 \mathrm{~K}$ and $30 \mathrm{bar}$ both without $k_{i j}$ 's (figure 15a) and with $k_{i j}$ 's (figure 15b). While case E clearly gives the best predictions without binary interaction parameters, all cases perform well and almost identically with binary interaction parameters.

Figure 16 compares the predictions of the modeling approaches with experimental data at 250 $\mathrm{K}$ and 25 bar (figure 16a) and $230 \mathrm{~K}$ and 65 bar (figure 16b). In both cases all kij's are set to zero. It is clear that case $\mathrm{E}$ is fully satisfactory at low pressures. Close to the critical pressure of the mixture the accuracy of the liquid phase predictions tend to deteriorate for case E. This is undoubtedly caused by the poor representation of the $\mathrm{CO}_{2}+$ methane binary near the 
critical point when the binary interaction parameter is ignored for case E. While not quite as good as those of case E the predictions with case D are clearly better than the other CPA approaches.

The $\mathrm{CO}_{2}+$ ethane + n-eicosane predictions were compared to experimental data from the $\mathrm{PhD}$ work of Al-Marri [65] at $338.7 \mathrm{~K}$ and 104.4 bar. When the $k_{i j}$ 's are assumed to be zero Table 17 suggests that very good predictions are obtained for especially the liquid phase with case E, whereas case $\mathrm{C}$ actually predicts the vapor phase composition more accurately, especially the small amount of n-eicosane in the vapor phase.

Figures 17 illustrate the predictions. Visually all models predict the vapor phase composition identically, but based on the deviations it seems that case $\mathrm{C}$ most accurately predicts the amount of n-eicosane in the vapor phase. For these large n-alkanes, however, the experimental accuracy may be questionable, especially for the small amount of n-eicosane in the vapor phase. In the liquid phase both quadrupolar approaches are clearly superior to case $\mathrm{C}$ (and case A), despite using fewer pure compound parameters.

As in the case of the $\mathrm{CO}_{2}+$ methane + ethane system the predictions are very similar when binary interaction parameters are employed. Case $\mathrm{E}$ still performs best of the four approaches, although the liquid phase predictions with case E actually becomes slightly poorer, than without binary interaction parameters. 
Table 17. CPA and qCPA deviations between model predictions and experimental composition data from Refs. [63-65] for the VLE of the two ternary systems $\mathrm{CO}_{2}(1)+$ methane(2) + ethane(3) and $\mathrm{CO}_{2}(1)$ + ethane(2) + eicosane(3) using four of the modeling approaches. The pressure and temperature range is $230-250 \mathrm{~K}$ and $25-65$ bar for the former system and $338.7 \mathrm{~K}$ and 104 bar for the latter system. The predictions have been performed both with and without interaction parameters as indicated in the table.

\begin{tabular}{|c|c|c|c|c|c|c|}
\hline & \multicolumn{6}{|c|}{ \%AAD in composition } \\
\hline & $x_{1}$ & $x_{2}$ & $x_{3}$ & $y_{1}$ & $y_{2}$ & $y_{3}$ \\
\hline $\mathrm{CO}_{2}(1)+$ methane(2)+ethane(3) & \multicolumn{6}{|c|}{$k_{i j}=0$} \\
\hline Case A & - & - & - & - & - & - \\
\hline Case C & 6.2 & 70.0 & 6.9 & 13.3 & 31.6 & 18.2 \\
\hline Case D & 4.6 & 45.5 & 5.8 & 10.1 & 20.3 & 13.8 \\
\hline Case E & 5.3 & 16.4 & 2.9 & 6.6 & 4.2 & 7.6 \\
\hline $\mathrm{CO}_{2}(1)+$ methane(2)+ethane(3) & \multicolumn{6}{|c|}{$k_{i j} \neq 0$} \\
\hline Case A & 4.6 & 22.0 & 4.4 & 8.6 & 5.6 & 10.3 \\
\hline Case C & 4.5 & 23.8 & 4.5 & 8.6 & 6.2 & 9.9 \\
\hline Case D & 4.7 & 22.9 & 4.6 & 8.5 & 5.8 & 10.2 \\
\hline Case E & 4.8 & 22.3 & 4.7 & 8.4 & 5.3 & 9.9 \\
\hline $\mathrm{CO}_{2}(1)+$ ethane(2)+eicosane(3) & \multicolumn{6}{|c|}{$k_{i j}=0$} \\
\hline Case A & - & - & - & - & - & - \\
\hline Case C & 17.9 & 4.8 & 38.3 & 0.7 & 1.0 & 26.9 \\
\hline Case D & 10.7 & 4.1 & 25.4 & 1.5 & 1.4 & 37.8 \\
\hline Case E & 0.5 & 3.9 & 7.1 & 2.7 & 2.8 & 60.8 \\
\hline $\mathrm{CO}_{2}(1)+$ ethane(2)+eicosane(3) & \multicolumn{6}{|c|}{$k_{i j} \neq 0$} \\
\hline Case A & 9.0 & 4.3 & 22.4 & 1.8 & 2.1 & 57.7 \\
\hline Case C & 11.0 & 4.0 & 25.5 & 1.5 & 1.4 & 55.0 \\
\hline Case D & 9.5 & 4.2 & 23.2 & 1.7 & 1.9 & 52.8 \\
\hline Case E & 4.2 & 3.8 & 14.1 & 2.2 & 2.3 & 59.0 \\
\hline
\end{tabular}




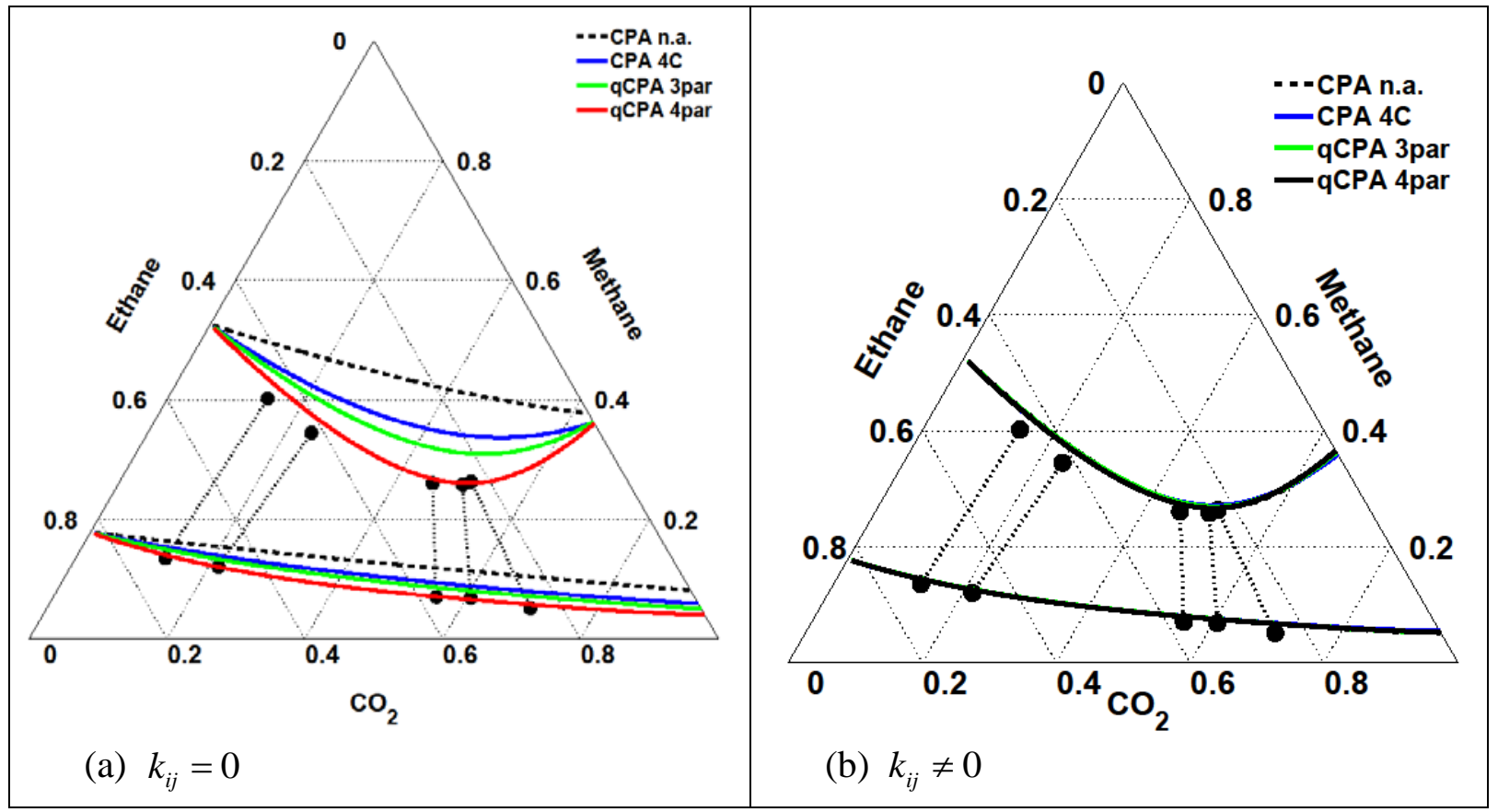

Figure 15. Predictions compared to experimental data for the $\mathrm{CO}_{2}+$ methane + ethane VLE at $250 \mathrm{~K}$ and 30 bar. (a) No interaction parameters are employed $\left(\mathrm{k}_{\mathrm{ij}}=0\right)$ and (b) binary interaction parameters are employed. Circles and dotted lines are experimental data are from Ref. [64] and experimental tie lines respectively.

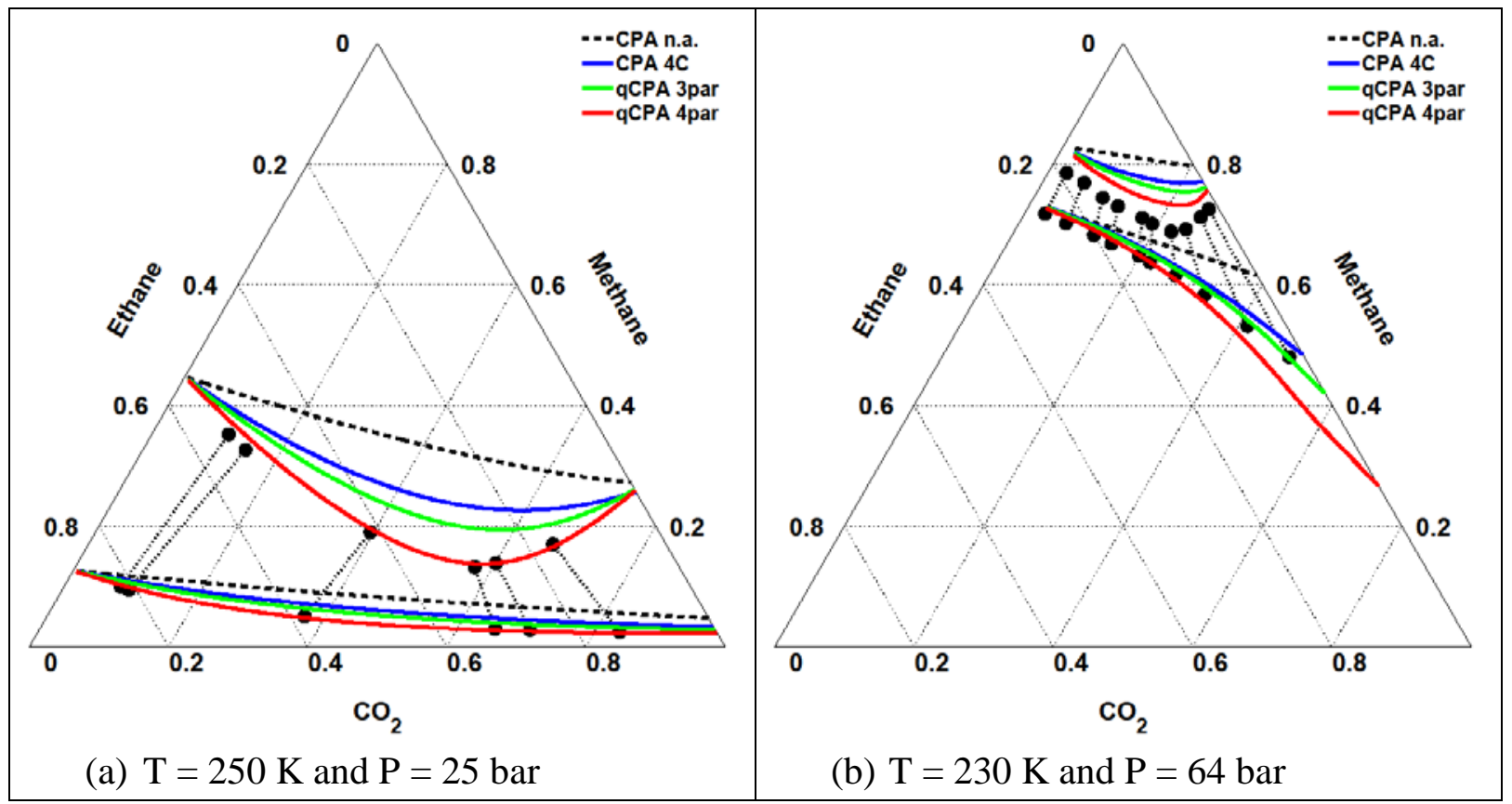

Figure 16. Pure predictions compared to experimental data for the $\mathrm{CO}_{2}+$ methane + ethane VLE at (a) $250 \mathrm{~K}$ and 25 bar and (b) $230 \mathrm{~K}$ and 65 bar. In both cases no interaction parameters are employed $\left(\mathrm{k}_{\mathrm{ij}}=0\right)$. Circles and dotted lines are experimental data are from Refs. $[63,64]$ and experimental tie lines respectively. 


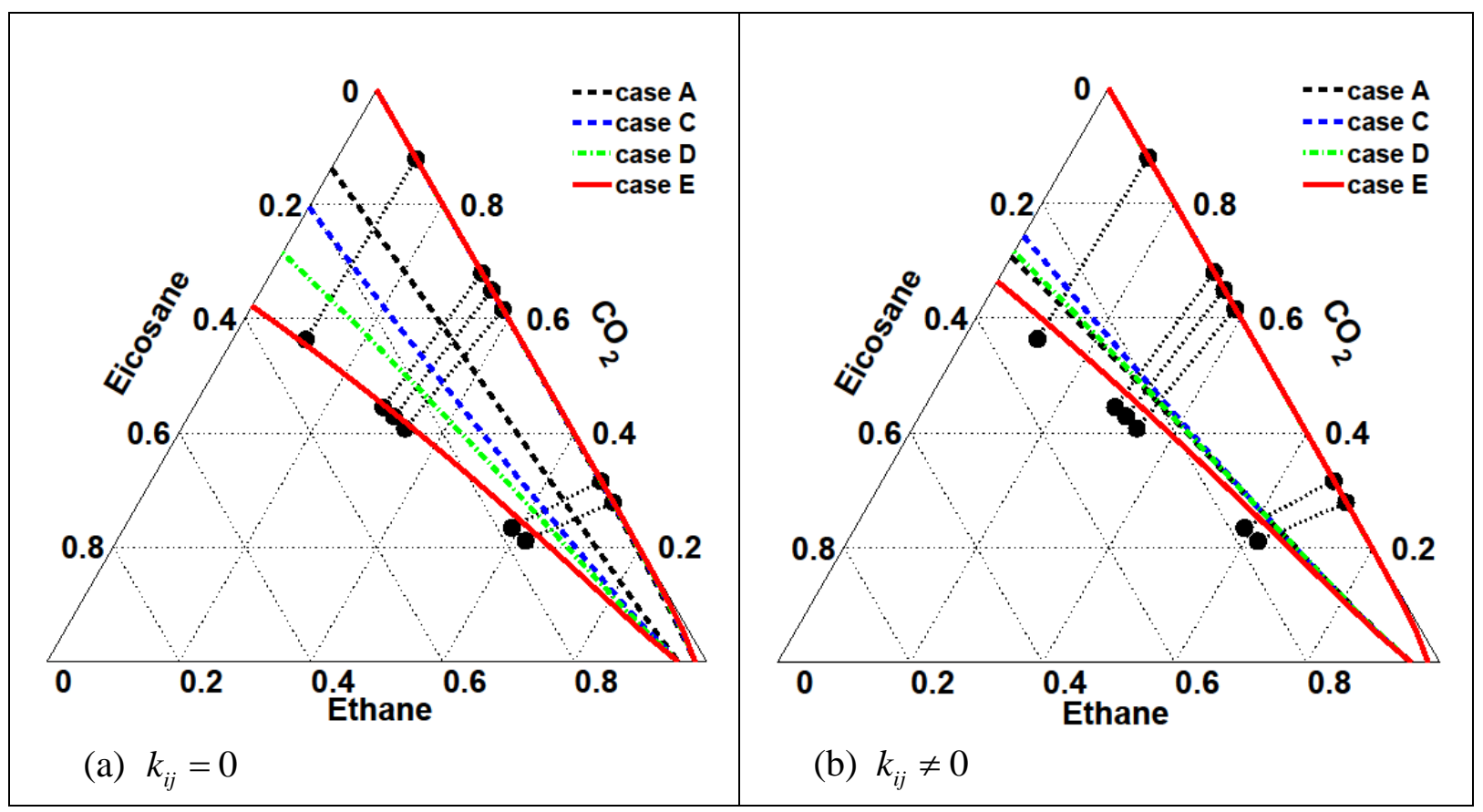

Figure 17. Predictions compared to experimental data for the CO2 + ethane + eicosane VLE at $338.7 \mathrm{~K}$ and 104.4 bar. (a) No interaction parameters are employed $\left(k_{i j}=0\right)$ and (b) interaction parameters are employed as usual. Circles and dotted lines are experimental data are from [65] and experimental tie lines respectively.

\subsection{Derivative Properties of $\mathrm{CO}_{2}$ at the saturation region}

As the pure compound parameters of $\mathrm{CO}_{2}$ for the modeling approaches investigated by Bjørner and Kontogeorgis [56,57] have been correlated to the saturated liquid density and saturated vapor pressure it is of interest to evaluate the models for their ability to predict other derivative properties at saturation. We have, thus, compared the prediction of several derivative properties for $\mathrm{CO}_{2}$, both in the liquid and vapor phase against pseudo-experimental data from the Span and Wagner EoS for pure $\mathrm{CO}_{2}$ [66].Of course, conclusions on the accuracy of CPA will depend on the accuracy of the pseudo-experimental data from the Span-Wagner EoS for the various properties of $\mathrm{CO}_{2}$, an accuracy which is difficult to assess.

The temperature range of this investigation is $\mathrm{T}=216-300 \mathrm{~K}$, the immediate vicinity around the critical point ( $\mathrm{T}=304.13 \mathrm{~K}$ and $\mathrm{P}=73.8 \mathrm{bar}$ ) is ignored as the uncertainty with the Span and Wagner EoS, and with the investigated equations of state, becomes significant at these conditions.

Tables 18 and 19 compare, in terms of \%AAD, the equations of state for their ability to predict the vapor density of $\mathrm{CO}_{2}$ as well as several derivative properties (the speed of sound, the isobaric and isochoric heat capacity, the Joule-Thomson coefficient and the enthalpy of vaporization) at saturation in the liquid and vapor phase respectively. Theoretically the addition of a quadrupolar term should improve the prediction of the derivative properties due to the physically more correct model and the improved density description in the liquid 
phase. However, with the exception of the residual isobaric heat capacity in the liquid phase, $C_{P, l i q}^{\text {res,sat }}$, it is observed that CPA without association often performs somewhat better for $\mathrm{CO}_{2}$ than the more sophisticated models, especially in the vapor phase, where the EoS is superior for $\mathrm{CO}_{2}$ both in the vapor density, isochoric heat capacity and Joule-Thomson coefficient. This is also the case for the heat of vaporization, where the EoS again performs better, possibly due to a more accurate vapor phase enthalpy. Nevertheless, the performance of the models is comparable for all properties in terms of \%AAD. Overall the predictions of most properties are satisfactory, considering that no parameters have been fitted to them. Noticeable exceptions to the otherwise satisfactory performance are the predictions of the residual isochoric and isobaric heat capacities in the vapor phase as well as the isochoric heat capacity in the liquid phase (except for CPA without association).

Table 18. \%AAD values for the liquid phase properties $u_{\text {liq }}^{\text {sat }}, C_{P, \text { liq }}^{\text {res,sat }}, C_{V, \text { liq }}^{\text {res, sat }}$ and $\mu_{J T, l i q}^{\text {sat }}$ as well as $\Delta H^{\text {vap }}$ for $\mathrm{CO}_{2}$ at saturation using CPA where $\mathrm{CO}_{2}$ is treated either as a nonassociating (n.a.) or self-associating compound (scheme 4C), and qCPA with either three or four parameters. The temperature range is $\mathrm{T}=216-300 \mathrm{~K}$. Pseudo-experimental data are from the Span and Wagner EoS [66]. $u$ represents the speed of sound, $\mu$ the Joule-Thomson coefficient and $\Delta H^{\text {vap }}$ the heat of vaporization.

\begin{tabular}{llllll}
\hline Modeling approaches & $u_{\text {liq }}^{\text {sat }}$ & $C_{P, l i q}^{\text {res,sat }}$ & $C_{V, l i q}^{\text {res, sat }}$ & $\mu_{J T, l i q}^{\text {sat }}$ & $\Delta H^{\text {vap }}$ \\
\hline CPA, n.a & 13.2 & 7.6 & 10.7 & 6.6 & 7.7 \\
CPA, 4C & 13.2 & 4.8 & 35.1 & 8.7 & 9.9 \\
qCPA, 3par & 13.0 & 5.2 & 23.8 & 6.2 & 9.6 \\
qCPA, 4par, set 1 & 13.0 & 5.1 & 27.5 & 7.6 & 10.6 \\
qCPA, 4par, set 2 & 13.1 & 5.4 & 24.2 & 7.5 & 10.0 \\
\hline
\end{tabular}

Table 19. \%AAD values for the vapor phase properties $\rho_{\text {vap }}^{\text {sat }}, u_{\text {vap }}^{\text {sat }}, C_{P \text {,vap }}^{r e s, a t}, C_{V \text {,vap }}^{r e s, \text { sat }}$, and $\mu_{J T \text {,vap }}^{\text {sat }}$ of $\mathrm{CO}_{2}$ at saturation using $\mathrm{CPA}$ where $\mathrm{CO}_{2}$ is treated either as a non-associating (n.a.) or selfassociating compound (scheme 4C), and qCPA with either three or four parameters. The temperature range is $\mathrm{T}=216-300 \mathrm{~K}$. Pseudo-experimental data are from the Span and Wagner EoS [66].

\begin{tabular}{lccccc}
\hline Modeling approaches & $\rho_{\text {vap }}^{\text {sat }}$ & $\boldsymbol{u}_{\text {liq }}^{\text {sat }}$ & $C_{P, \text { liq }}^{\text {res,sat }}$ & $C_{V, \text { liq }}^{\text {res, }}$ & $\mu_{J T, l i q}^{\text {sat }}$ \\
\hline CPA, n.a & 6.9 & 6.2 & 56.7 & 86.4 & 9.1 \\
CPA, 4C & 8.1 & 5.7 & 57.1 & 79.1 & 10.5 \\
qCPA, 3par & 8.5 & 6.0 & 59.3 & 84.8 & 10.4 \\
qCPA, 4par, set 1 & 9.5 & 6.0 & 60.6 & 84.5 & 11.0 \\
qCPA, 4par, set 2 & 9.7 & 5.9 & 60.7 & 85.0 & 11.0 \\
\hline
\end{tabular}


Figure 18 shows predictions of the (normalized) liquid and vapor isobaric and isochoric heat capacity respectively. It is clear from figure 18a that the liquid isobaric heat capacity of $\mathrm{CO}_{2}$ is modeled rather well through most of the saturation region when $\mathrm{CO}_{2}$ is modeled either with CPA and the 4C scheme or with qCPA. The predictions of all model approaches begin to deviate as the critical point is approached. On the other hand, figure $18 \mathrm{~b}$ shows that the trend of the liquid isochoric heat capacity is not captured by any model. Moreover the predictions in the vapor phase are quite poor for both the residual isochoric and isobaric heat capacity respectively.
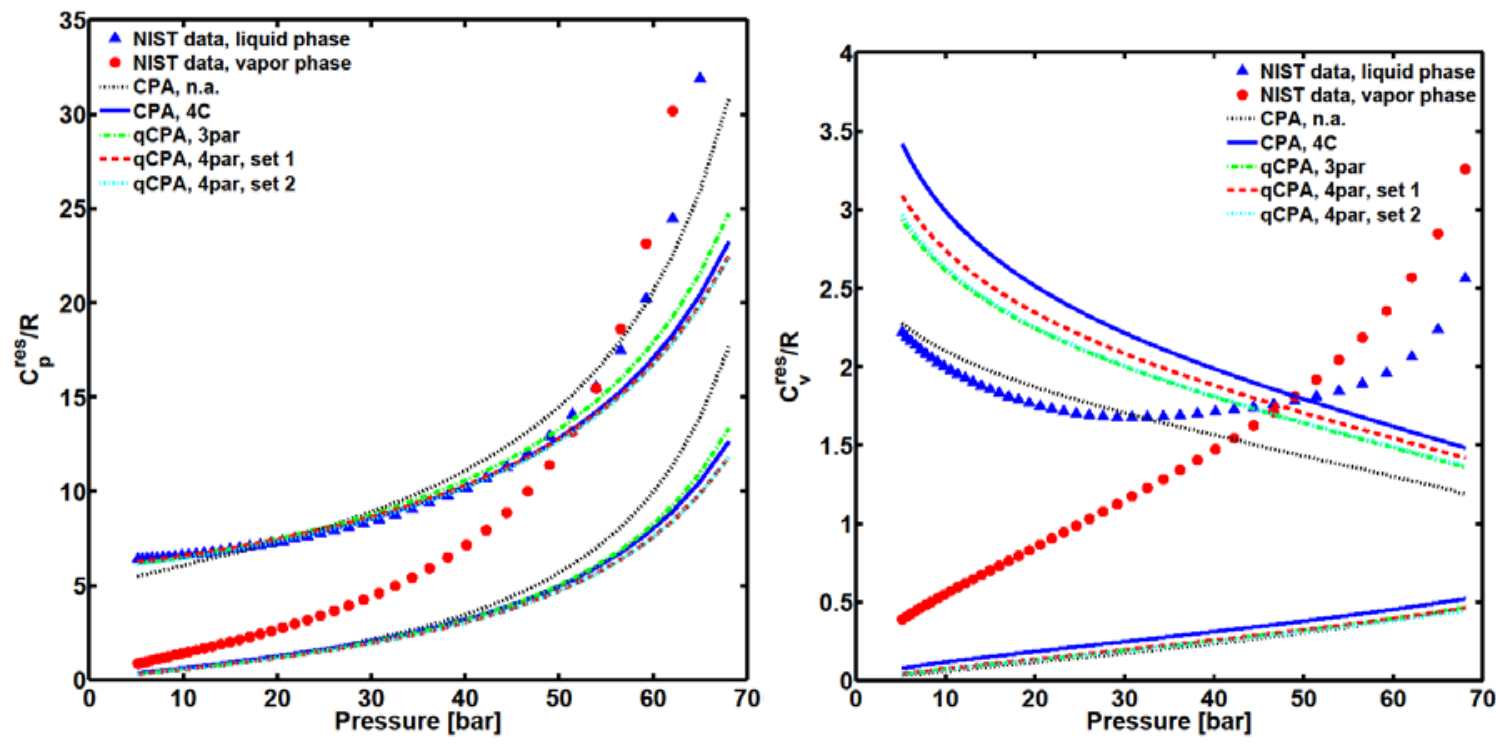

Figure 18. Normalized liquid and vapor residual isochoric (a) and isobaric (b) heat capacity predictions of $\mathrm{CO}_{2}$ at saturation with CPA and qCPA. Pseudo-experimental data are from the Span and Wagner EoS [66].

Figure 19 illustrates that the speed of sound in the vapor phase and the Joule-Thomson coefficient in the liquid phase are predicted quite well, although once again the performance begins to deteriorate close to the critical point. However, the liquid phase speed of sound and vapor phase Joule-Thomson coefficient predictions are quantitatively wrong and, moreover, the trend of the data is not fully captured. 

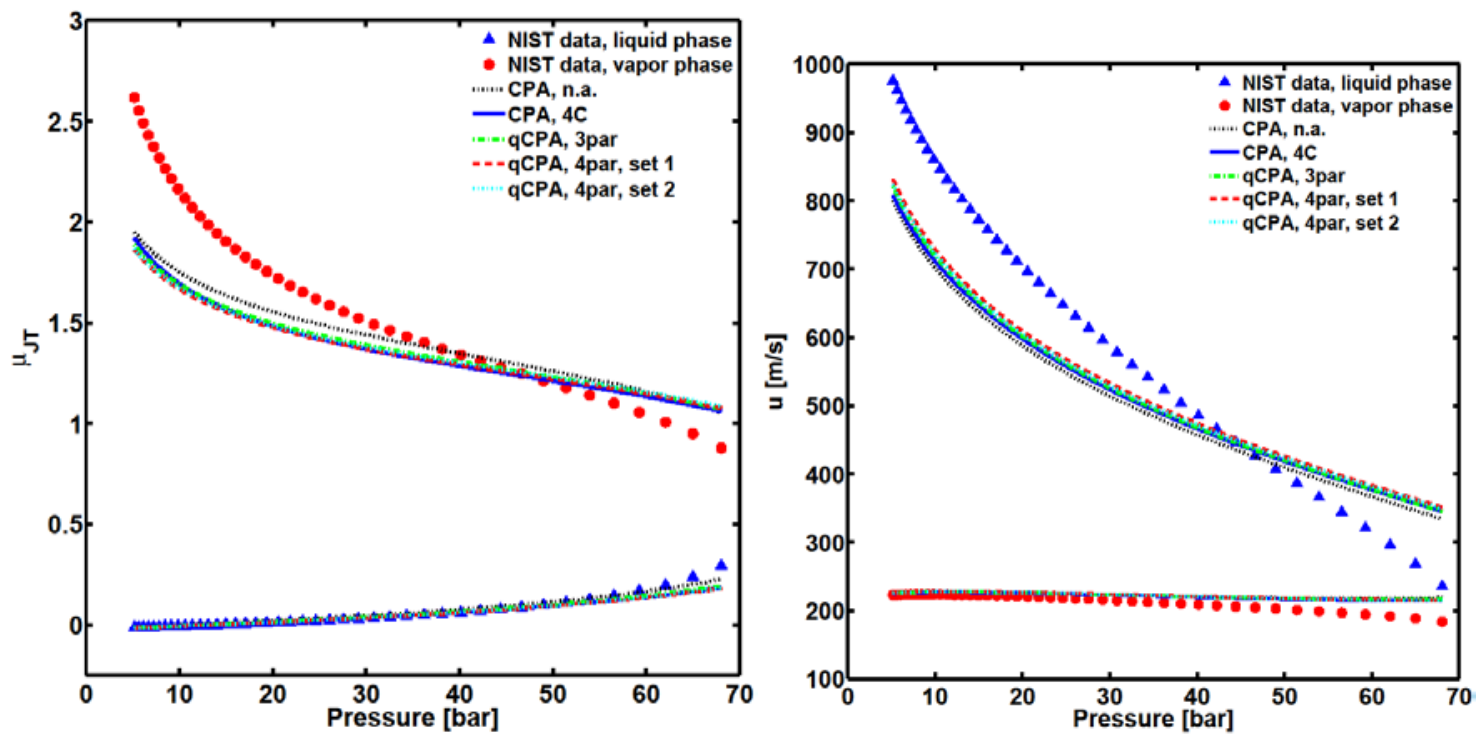

Figure 19. Liquid and vapor Joule-Thomson coefficient (a) and speed of sound (b) predictions of $\mathrm{CO}_{2}$ at saturation with CPA and qCPA. Pseudo-experimental data are from the Span and Wagner EoS [66].

Figure 20 shows the predicted heat of vaporization. All models predict the qualitative trend, but are less accurate as the critical pressure is approached. Again, CPA without association performs slightly better than the other modeling approaches close to the critical point.

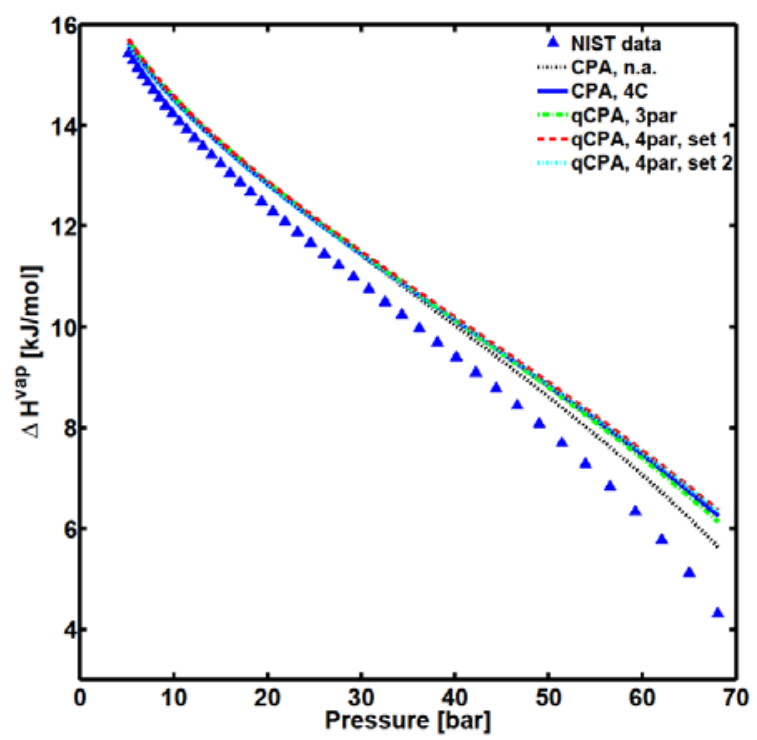

Figure 20. Heat of vaporization predictions of $\mathrm{CO}_{2}$ at saturation with CPA and qCPA. Pseudo-experimental data are from the Span and Wagner EoS [66]. 
Finally figure 21 provides a summary of results for several properties for the liquid or supercritical phase, see Bjørner and Kontogeorgis [56,57] for detailed results.

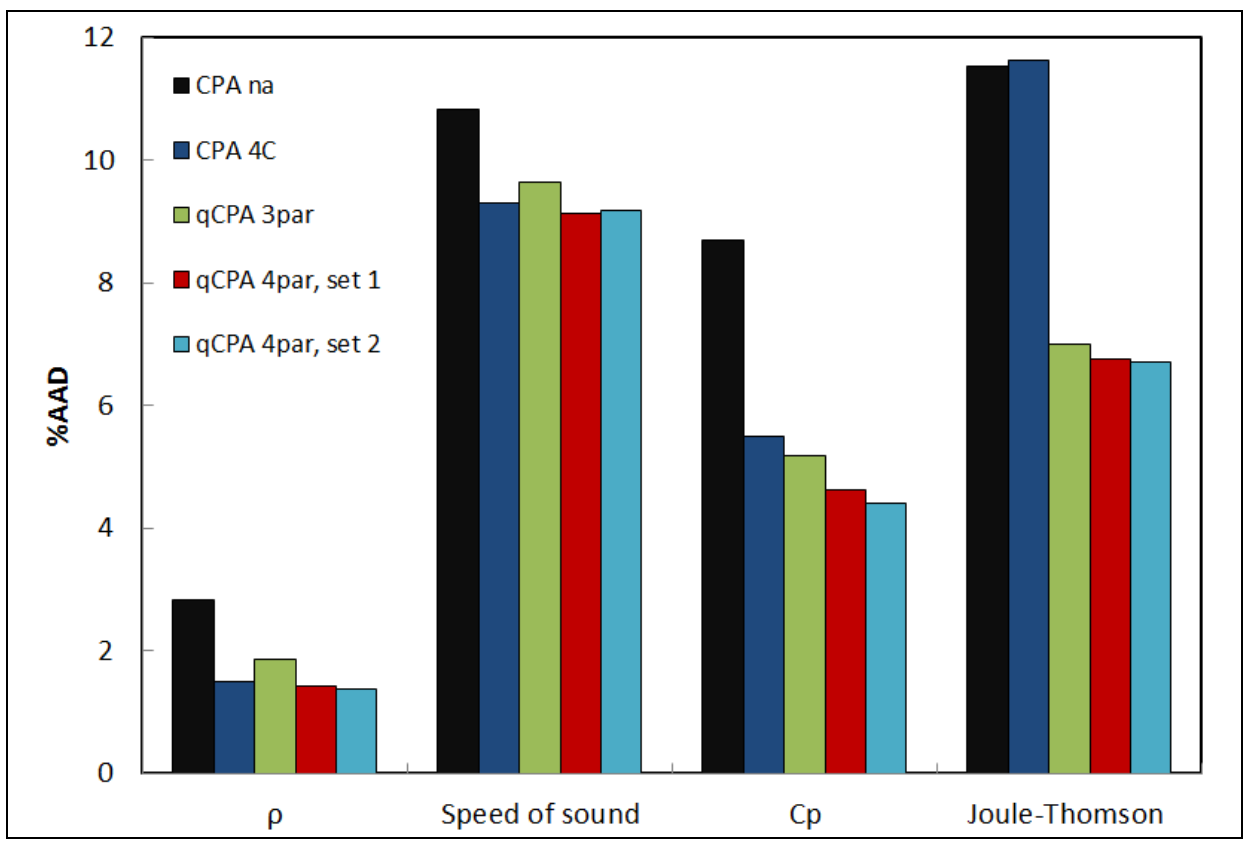

Figure 21. Model comparison of the overall \%AADs for the density, speed of sound, isobaric heat capacity and the Joule-Thomson coefficient in the liquid or supercritical phase using the five modeling approaches.

Overall it can be concluded (see references 56 and 57 for detailed results) that for most predicted properties, in both the saturation-, the compressed liquid- and the critical region, the qualitative performance is not significantly different for the various models (CPA n.a., CPA 4C and qCPA), and all modeling approaches predict the same trends. With the clear exception of $C_{V}^{r e s}$ all models generally perform satisfactorily considering that the model parameters have not been correlated to any of these properties, rendering the models purely predictive.

Regarding the density and the derivative properties qCPA and CPA with the 4C scheme typically perform slightly better quantitatively than CPA without association (again with $C_{V}^{r e s}$ as the exception). The predictions are only marginally improved when the four parameter version of qCPA is employed, rather than the three parameter version. In most cases qCPA and CPA yield similar predictions, however, the Joule-Thomson coefficient is, at least in terms of \%AAD, predicted significantly better with the various qCPA approaches for the liquid and supercritical phases.

Considering that qCPA should result in a physically more correct model, the improvement, at least for the quadrupolar term, is clearly smaller than one might have expected. Of course 
part of the explanation for this is that most of the pure compound predictions with inert CPA are quite good to begin with. Another reason may be that the artificially large attractive energies for e.g. inert CPA may compensate quite well for the added energetic quadrupole term as long as there are no cross interactions.

\section{Case study IV: Prediction of multicomponent LLE for water-glycol-hydrocarbons}

A few years ago almost no multicomponent data existed for water-glycol-hydrocarbons (especially alkanes), possibly due to the very low solubilities involved. Earlier efforts (Sentenac et al., [67]) were not very successful, but some years later $([68,69])$ a wide range of such data have been published for ethylene glycol (MEG) - water with diverse alkanes and other hydrocarbons. Such data offer an excellent test of the predictive capabilities of association models, and this is illustrated here for CPA. All pure fluid parameters are obtained from literature $[70,71,19]$ and figures 22-25 show the correlation of LLE for MEG and water with two alkanes. Please notice that in these figures experimental data from different sources are shown. We can see that the experimental data e.g. for MEG-hexane are not in very good agreement with each other and there is deviation especially compared to older data by Derawi et al. [72]. Still the correlation performance of CPA is satisfactory with a single temperature-independent $k_{i j}$ (for MEG-hexane: around 30\% for the alkane solubility in MEG and 10\% for MEG in HC phase).

For water-alkanes, CPA has been used with $k_{i j}$ obtained from a previously published correlation $\left(k_{i j}=-0.026 \cdot(\right.$ carbon number $\left.)+0.195\right)$. Very satisfactory results are obtained for the mutual solubilities, as can be seen in Figures 24 and 25. It is very interesting that these new experimental LLE data do not show the minimum on the hydrocarbon's content in the aqueous phase, for which there has been so much discussion (about its origin e.g. due to a possible link to hydrophobic phenomenon and the apparent inability of association models to describe it). 


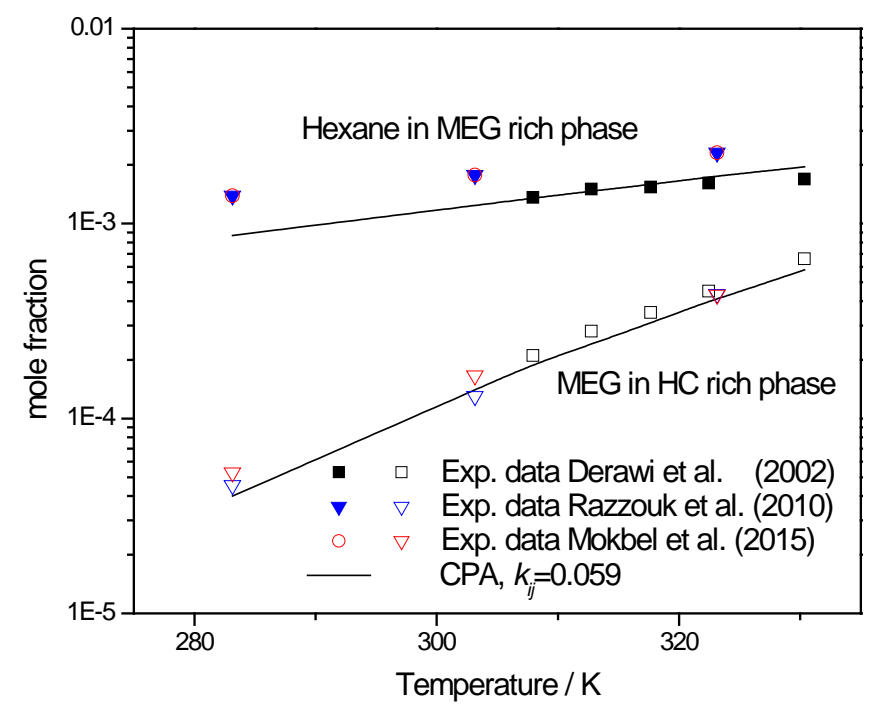

Figure 22. MEG - Hexane LLE. Experimental data (points) and CPA predictions (lines, $k_{i j}=0.059$ [73])

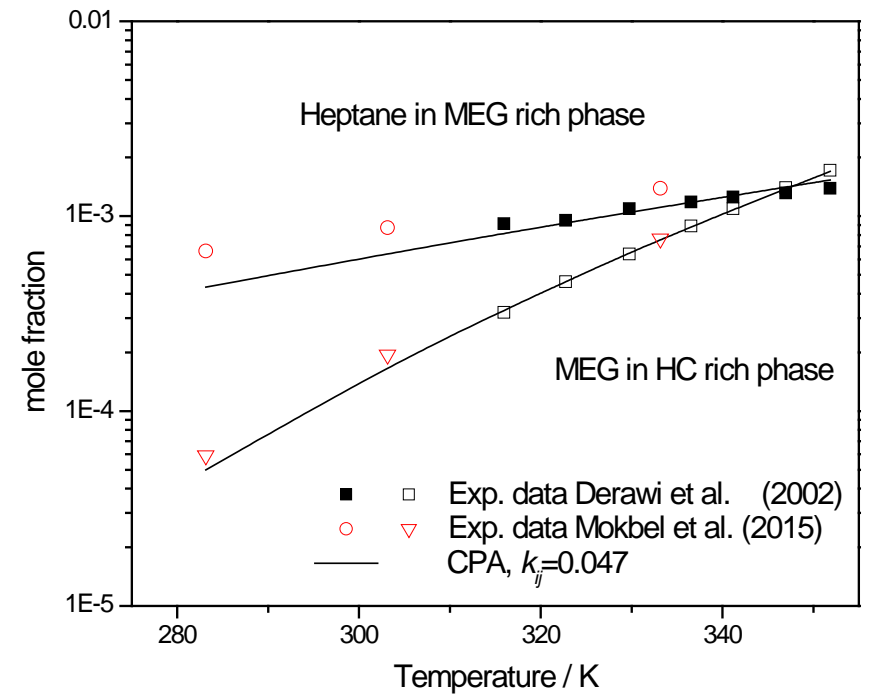

Figure 23. MEG - Heptane LLE. Experimental data (points) and CPA predictions (lines, $k_{i j}=0.047$ [73]) 


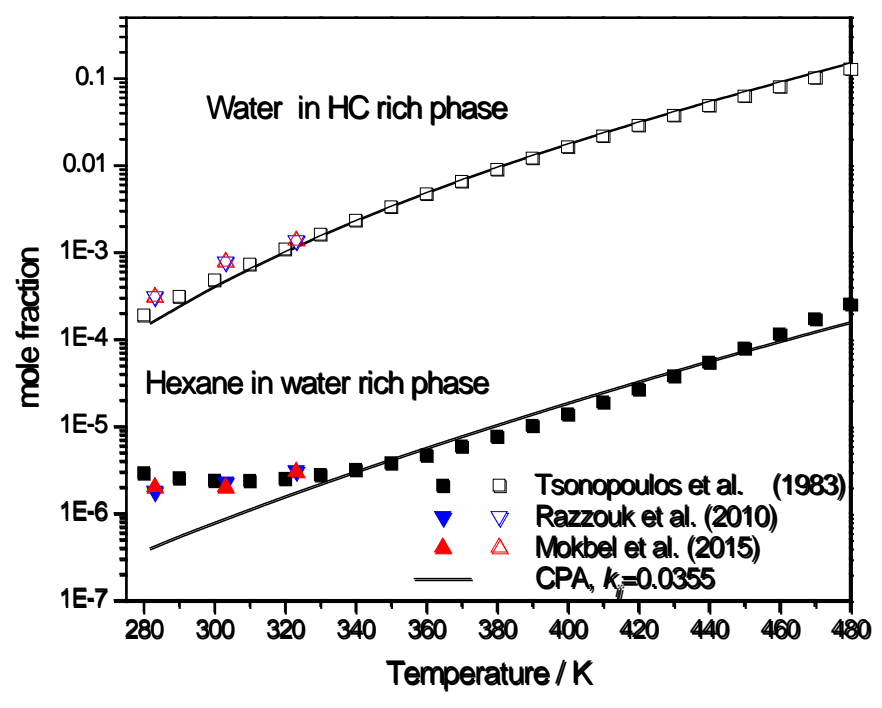

Figure 24. Water - Hexane LLE. Experimental data (and correlation of exp. data, ref. 75) (points) and CPA predictions (lines, $k_{i j}=0.0355$ )

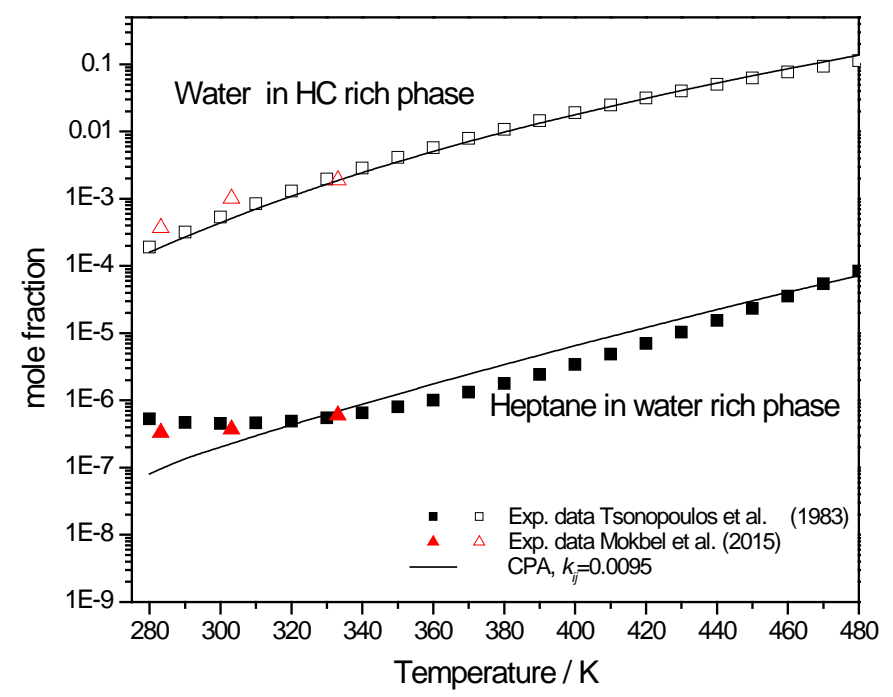

Figure 25. Water - Heptane LLE. Experimental data (and correlation of exp. data, ref. 75) (points) and CPA predictions (lines, $k_{i j}=0.0095$ ) 
Then, calculations have been performed for two of the MEG - water - normal alkanes systems for which there are LLE data. All binary interaction parameters were adopted from the corresponding binary systems. For water - MEG the binary interaction parameter was set equal to $k_{i j}=-0.028$ [74]. The results are summarized in Table 20 and for one characteristic system in figure 26. If the (often significant) experimental uncertainties are considered, then the results should be considered satisfactory, with the highest deviations seen for the alkane solubility in aqueous phase and the water solubility in the hydrocarbon phase.

Table 20. Average deviations from experimental data for the investigated ternary systems

\begin{tabular}{|c|c|c|c|c|c|c|c|}
\hline \multirow[b]{2}{*}{ System } & \multirow[b]{2}{*}{$\begin{array}{l}\text { Temp } \\
\text { (K) }\end{array}$} & \multicolumn{3}{|c|}{ Aqueous phase } & \multicolumn{3}{|l|}{ HC phase } \\
\hline & & $\begin{array}{l}\% A A D \\
\operatorname{inx}_{1}\end{array}$ & $\begin{array}{l}\% \text { AAD } \\
\text { in } x_{2}\end{array}$ & $\begin{array}{l}\% \text { AAD } \\
\text { in } x_{3}\end{array}$ & $\begin{array}{l}\% \text { AAD } \\
\text { in } x_{1}\end{array}$ & $\begin{array}{l}\% \text { AAD } \\
\text { in } x_{2}\end{array}$ & $\begin{array}{l}\% \text { AAD } \\
\text { in } x_{3}\end{array}$ \\
\hline $\begin{array}{l}\text { MEG (1) - Water (2) - } \\
\text { n-Hexane (3) (Exp. Data } \\
\text { from [68]) }\end{array}$ & $283-333$ & 0.015 & 0.024 & 44.4 & 41.5 & 43.5 & 0.022 \\
\hline $\begin{array}{l}\text { MEG (1) - Water (2) - } \\
\text { n-Hexane (3) } \\
\text { (Exp. Data from [69]) }\end{array}$ & $283-323$ & 0.017 & 0.024 & 59.9 & 14.5 & 39.3 & 0.015 \\
\hline $\begin{array}{l}\text { MEG (1) - Water (2) - } \\
\text { n-Heptane (3) } \\
\text { (Exp. Data from [69]) }\end{array}$ & 283-333 & 0.020 & 0.006 & 45.7 & 14.8 & 31.5 & 0.018 \\
\hline
\end{tabular}




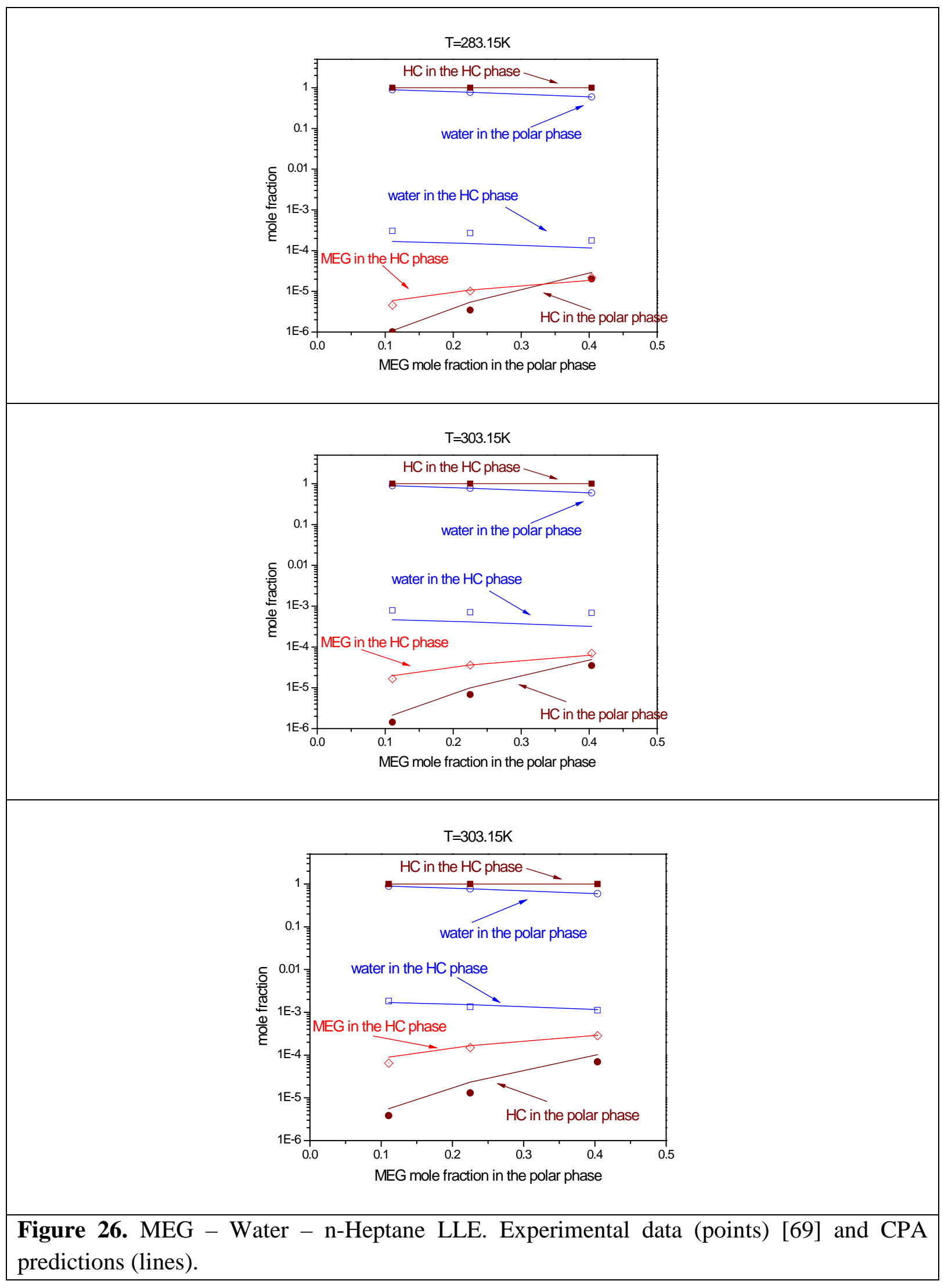




\section{Discussion and concluding remarks}

We have presented and briefly discussed four case studies which illustrate some of the capabilities and limitations of association models (CPA) in a number of applications of practical significance. We have illustrated applications of the model not just for phase equilibria (VLE, LLE, SLE) but also discussed the importance of other properties like excess enthalpies and derivative properties in parameter estimation and/or model validation.

We emphasized in several cases multicomponent calculations. Overall good results are obtained in many cases, and for many associating fluids, as also shown in literature, and the good results are extended to many predictions for multicomponent, multiphase VLLE as we saw in several cases in this work as well. Many more results are shown in literature [e.g. 4, 35, 52, 76-78].

Multicomponent calculations are one approach to validate the predictive capabilities of the models. Other predictive approaches for association models involve the concept of group contributions (GC); these has been mostly used for various SAFT models so far like SAFTgamma-Mie [3] and PC-SAFT and they have not been discussed in this work. Fully predictive versions of CPA/SAFT and other association models imply having predictive e.g. GC methods for estimating all pure compound parameters including the association ones as well as all binary interaction parameters, typically both the dispersion-based $k_{i j}$ and an occasionally employed additional cross-association parameter. There have been interesting attempts e.g. by Haslam et al. [79] using the Hudson-McCoubrey theory and by Breil et al. [80] using the homomorph approach, but there is need for much more research in this area and possibly development of generalized approaches. It might be interesting to investigate how association parameters (pure and interaction ones) can be connected to externally obtained measures of association like the Kamlet-Taft solvatochromic parameters, experimental values for the hydrogen bonding enthalpy and entropy as well as the Drago approach for estimating cross association enthalpies.

A difficulty in the model validation esp. for several complex fluids is the lack of experimental data and also the uncertainty in the measurements, particularly pronounced for mixtures where the solubilities are very low e.g. glycols in the vapor phase and water or other polar compounds in the hydrocarbon-rich phase. We have seen this in the last case study.

Another issue we discussed is whether adding more physics e.g. including separate polar and quadrupolar interactions is of importance. In general, this has not led to conclusive results for practical applications. While the results shown in this work are with CPA, a review of the numerous literature studies [4] with diverse polar and quadrupolar versions of SAFT yield the same conclusions. Good results are obtained for mixtures of polar/quadrupolar molecules with alkanes (often with $k_{i j}=0$ ), and good predictions are seen also for excess enthalpies. When, however, interaction parameters are introduced and/or when mixtures with the polar/quadrupolar molecules with associating molecules are considered (e.g. $\mathrm{CO}_{2}$-water or ketones-water), then the impact of additional polar and/or quadrupolar terms is very small. In the context of CPA, we have previously carried out several studies with polar systems 
(acetates, ketones, esters, ethers .....) in mixtures with water, inert compounds, etc. where multicomponent and multiphase equilibria have been considered [76-78]. In all cases the predictions have been satisfactory without additional polar terms. Earlier some researchers $[81,4]$ have treated polar compounds like acetone as pseudo-associating but, while this approach is as satisfactory as an explicit treatment of polarity in mixtures with hydrocarbons, the results are not very satisfactory for multicomponent systems [77] and is thus not recommended. Even for binary systems, sometimes, e.g. for sulfolane-alkanes, the results are not very satisfactory and the temperature dependency of the solubilities for LLE is not wellcaptured when sulfolane is treated as pseudo-associating (see ref. 4). Notice that sulfolane is a highly polar compound with a dipole moment of $4.8 \mathrm{D}$, immiscible with several hydrocarbons over an extensive temperature range.

Most successful results presented in the literature with association models employ the "classical" by now and widely used "2B" scheme for alcohols and most amines and "4C" scheme for water and glycols. We use here the widely accepted terminology of Huang and Radosz [39]. For acids, the "1A" scheme is used, but there are some issues, see below. Some researchers (e.g. Breil and Kontogeorgis, [38] and Avlund et al. [82]) have also used some "more advanced" association schemes for multifunctional compounds like glycols, glycolethers and alkanolamines. They have then tested these schemes against pure compound data (vapor pressures and liquid densities) and mixtures with e.g. alkanes and water. They also compared the results to the classical " $4 \mathrm{C}$ " schemes often used for glycols and alkanolamines. It appears that not much improvement is offered with the more advanced association schemes and thus there is little to be gained e.g. by differentiating between $\mathrm{OH}$ and amine group parameters in alkanolamines or explicitly accounting for the -O- groups in the heavier glycols and glycolethers. Alkanolamines are mostly relevant in aqueous $\mathrm{CO}_{2} / \mathrm{H}_{2} \mathrm{~S}$ mixtures where reaction effects may need to be incorporated. However, there are also extensive data for mixtures of aqueous alkanolamines with other compounds (methane, ethane, propane, up to hexane). These have been studied with a PR-CPA model by Wang et al. [83] with rather satisfactory results, but typically temperature-dependent interaction parameters are needed. Another challenge for these systems is that the interaction parameter between alkanolamine and alkane is, for most systems, not available and should be fitted based on the ternary data. Thus, such calculations cannot be considered to be fully predictive.

However, the biggest challenges we have encountered in this respect (i.e. for strongly polar and associating systems) are mixtures with organic acids e.g. acetic acid and benzoic acid (particularly in aqueous systems). We do not think that the problems in this case are associated to the lack of a polar term but are more connected to limitations of the Wertheim framework and the use of the rather artificial " $1 \mathrm{~A}$ " scheme for organic acids. The Wertheim framework needs "further" improvements e.g. to account for intramolecular association and hydrogen-bonding co-operativity. There have been some promising results [84-86] but from the practical point of view they are not very satisfactory e.g. description of glycolether-water closed loops is only qualitatively correct. Moreover, in most cases (and almost always for phase equilibria) inclusion of intramolecular association has not resulted in improved results 
compared to the simpler version of the association model where such effects are not included [87].

In all the above calculations, the association models (CPA in this case) are used, as is, i.e. there are no "significant changes" in the original framework (maybe with the exception of the discussion of the quadrupolar CPA). Oil mixtures require a characterization procedure and successful results have been presented for both CPA and other SAFT variants but the amount of experimental data is small and more measurements are needed. Progress has been made also with asphaltenes (e.g. Arya et al. [88]) and results are available with CPA, PC-SAFT and other SAFT variants [89,90]. We believe that explicit inclusion of the association is crucial for obtaining good results and we have shown that in a series of publications [e.g. 88] but others $[89,90]$ have obtained also good results with PC-SAFT using only the nonassociation contributions of the models. There are several data but again the quality and quantity of the data is not sufficient and appropriate characterization of asphaltenes is difficult.

Electrolyte solutions require separate contributions for the long- and short-range electrostatic interactions and maybe even for solvation effects and they are considered in another recent review [16]. Another area where coupling of CPA (or other SAFT models) with another framework is needed is interfaces e.g. for calculation of interfacial tension and (multicomponent) adsorption. Both CPA and other SAFT models have been combined with frameworks like MPTA and DFT for estimating multicomponent adsorption but only CPA [91,92] has been applied to polar adsorption e.g. of alcohols and water. The results are not conclusive and it is not always clear that the association term helps. More work is needed. The same is true for the prediction of interfacial tensions where much research has been done with both CPA [93, 94] and PC-SAFT [95,96]. The models are coupled with either the DGT or DFT frameworks, with the latter being semi-predictive. Here good results are obtained in several cases but the numerics is sometimes difficult and there are problems for some systems e.g. ethanol-hexane. We suspect that for interfacial/adsorption phenomena, the effect of interaction parameters and in general parameter estimation is much more important than for bulk properties/phase equilibria. 


\section{References}

[1] J. Gross and G. Sadowski, Ind. Eng. Chem. Res. 40, 1244 (2001).

[2] F.J. Blas and L.F. Vega, J. Chem. Phys. 115, 4355 (2001).

[3] A. Lymperiadis, C.S. Adjiman, A. Galindo and George Jackson, J. Chem. Phys.127, 234903 (2007).

[4] G.M. Kontogeorgis and G.K. Folas, Thermodynamic models for industrial applications. From Classical and Advanced mixing rules to association theories, $1^{\text {st }}$ ed. (Wiley, NY, 2010).

[5] J-Ch. de Hemptinne, J-M. Ledanois, P. Mougin and A. Barreau, Select Thermodynamic models for process simulation. A practical guide using a three steps methodology, $1^{\text {st }}$ ed. (Editions Technip, 2012).

[6] C. McCabe and A. Galindo, Chapter 8. SAFT Associating Fluids and Fluid Mixtures in Applied Thermodynamics of Fluids Edited by A.R.H. Goodwin, J.V.Sengers, C.J.Peters, RSC Publishing (2010).

[7] G.M. Kontogeorgis, Chem. Eng. Res. Design, 91 (10), 1840 (2013).

[8] G.M. Kontogeorgis and I.G. Economou, J. Super. Fluids, 55, 421 (2010).

]9] E.A. Muller, K.E. Gubbins, Ind.Eng.Chem.Res., 40(10), 2193 (2001)

[10] I.G. Economou, Ind. Eng. Chem. Res. 41, 953 (2002).

[11] P.C.V. Tybjerg, G.M. Kontogeorgis, M.L. Michelsen and E.H. Stenby, Fluid Phase Equilib. 288 (12), 128 (2010).

[12] X. Liang, G. Aloupis and G.M. Kontogeorgis, J. Chem. Eng. Data, 62 (9), 2592 (2017).

[13] A. Grenner, I. Tsivintzelis, G.M Kontogeorgis, I.G. Economou and C. Panayiotou, Ind. Eng. Chem. Res. 47, 5636 (2008).

[14] I. Tsivintzelis, A. Grenner, G.M Kontogeorgis and I.G. Economou, Ind. Eng. Chem. Res. 47, 5651 (2008).

[15] G.M. Kontogeorgis, E.C. Voutsas, I.V. Yakoumis and D.P. Tassios, Ind. Eng. Chem. Res. 35, 4310 (1996).

[16] G.M. Kontogeorgis, B. Maribo-Mogensen, K. Thomsen, The Debye-Hückel theory and its importance in modeling electrolyte solutions, Fluid Phase Equilibria, accepted for publication (2018)

[17] I. Tsivintzelis, N.E. Musko, A. Baiker, J-D. Grunwaldt and G.M. Kontogeorgis, J. Supercritical Fluids, 63, 199 (2013).

[18] I. Tsivintzelis, G.M. Kontogeorgis, M.L. Michelsen and E.H. Stenby, AlChE J. 56, 2965 (2010).

[19] I. Tsivintzelis, G.M. Kontogeorgis, M.L. Michelsen and E.H. Stenby, Fluid Phase Equilib. 306, 38 (2011).

[20] F. Comelli and R. Francesconi, J. Chem. Eng. Data, 42, 705 (1997).

[21] J. A. V. Butler, D. W. Thomson and W. H. MacLennan, J. Chem. Society, 1933, 674-686.

[22] M. Broul, K. Hlavaty and J. Linek, Collection of Czechoslovak Chemical Communications, 34, 3428 (1969).

[23] H. Schuberth, Zeitschrift für Physikalische Chemie (Leipzig), 255, 165 (1974). 
[24] J. Griswold and S. Y. Wong, Chemical Engineering Progress Symposium Series 48, 18 (1952).

[25] W. Schroeder, Chemie Ingenieur Technik, 30, 523 (1958).

[26] S. Yunhai, L. Honglai, W. Kun, X. Wende and H. Ying, Fluid Phase Equilib. 234, 1 (2005).

[27] L. Abello, J. Chim. Phys. Phys.- Chim. Biol. 70, 1355 (1973).

[28] M. Yu. Panov, XI. Vestn. Leningr. Univ. Fiz. Khim. 10, 149 (1976).

[29] G.C. Benson, J. Phys. Chem. 67, 858 (1963).

[30] R.F. Lama, Benjamin C.-Y. Lu, J. Chem. Eng. Data, 10, 216 (1965).

[31] I. Tomaszkiewicz, S.L. Randzio, P. Gierycz, Thermochmica Acta, 103, 281 (1986).

[32] J.M. Simonson, D.J. Bradley, R.H. Busey, J. Chem. Thermodynamics, 19, 419 (1987)

[33] C.J. Wormald, L. Badock, M.J. Lloyd, J. Chem. Thermodynamics 28, 603 (1996).

[34] I. Tsivintzelis, A. Shahid, G.M. Kontogeorgis, J. Chem. Eng. Data 59, 2955 (2014).

[35] I. Tsivintzelis, G.M. Kontogeorgis, J. Supercritical Fluids 104, 29 (2015).

[36] J.-H. Yoon, M.-K. Chun, W.-H. Hong, H. Lee, Ind. Eng. Chem. Res. 32, 2881 (1993).

[37] C. Jarne, S.T. Blanco, J. Fernandez, E. Rauzy, S. Otin, I. Velasco, Ind. Eng. Chem. Res. 43, 662 (2004).

[38] M.P. Breil, G.M. Kontogeorgis, Ind. Eng. Chem. Res. 48, 5472 (2009).

[39] H.S. Huang, M. Radosz, Ind. Eng. Chem. Res. 29, 2284 (1990).

[40] DIPPR, Design institute for physical properties, DIADEM professional, 2010, version 3.0.0 (Computer Program).

[41] M. Herskowitz, M. Gottlieb, J. Chem. Eng. Data, 29, 173 (1984).

[42] W.R. Parrish, K.W. Won, M.E. Baltatu, Proceedings of the 65th Annual GPA Convention 1986, San Antonio, TX, March 10-12.

[43] S.E.M. Hamam, G.C. Benson, M.K. Kumaran J. Chem. Therm. 17, 973 (1985).

[44] A.K. Mostafazadeh, K.R. Rahimpour, A.J. Shariati, Chem. Eng. Data 54, 876 (2009).

[45] B. Bestani, K.S. Shing, Fluid Phase Equilib. 50209 (1989).

[46] C.H. Twu, V. Tassone, W. Sim, S. Watanasiri, Fluid Phase Equilib., 228-229, 213 (2005).

[47] NIST Chemistry WebBook, NIST Standard Reference Database Number 69, http://webbook.nist.gov/chemistry/

[48] Dow Chemicals, Triethylene Glycol, Dow Chemicals brochure, 2007.

[49] L.H. Gjertsen, J.E. Vindstad, I.M. Malvik, A.O. Fredheim, presented at IGU Research Conference, Amsterdam, 2001.

[50] J.M. Campbell, Gas Conditioning and Processing. Volume1, $7^{\text {th }}$ Edition, Campbell Petroleum Series. (1990).

[51] GPSA. Engineering Data Book. Vol. II: 20-24 (1998).

[52] I Tsivintzelis, G.M. Kontogeorgis, Ind. Chem. Eng. Res. Design, 92, 2947 (2014). 
[53] A. Arya, B. Maribo-Mogensen, I. Tsivintzelis, G.M. Kontogeorgis, Ind. Eng. Chem. Res. 53, 11766 (2014).

[54] H.-J. Ng, H. Schroeder, Gas Processors Association Research Report, RR-177, 2002.

[55] M. Frost, G.K. Folas, N. Muro-Sune, F.R. Leon, M.P. Breil, N. von Solms, M.L. Michelsen, G.M. Kontogeorgis, in I. Tsivintzelis, B. Maribo-Mogensen, The Cubic-Plus-Association EoS, Parameters for pure compounds and interaction parameters, Technical Report, CERE-DTU, 2012 (unpublished).

[56] M.G. Bjørner, G.M. Kontogeorgis, Fluid Phase Equilib. 408, 151 (2016); 421, 104E (2016).

[57] M.G. Bjørner, G.M. Kontogeorgis, Mol. Physics, 114, 2641 (2016).

[58] M.G. Bjørner, G. Sin, G.M. Kontogeorgis, Fluid Phase Equilib. 414, 29 (2016).

[59] N.N. Shah, J.A. Zollweg and W.B. Streett, J. Chem. Eng. Data 36, 188 (1991).

[60] L.A. Webster and A.J. Kidnay, J. Chem. Eng. Data 46, 759 (2001).

[61] I. Nieuwoudt, and M. du Rand, J. Supercritical Fluids 22, 185 (2002).

[62] K.P. Wallis, P. Clancy, J.A. Zollweg, and W.B. Streett, J. Chem. Thermodyn. 16, 811 (1984).

[63] M. S.-W. Wei, T.S. Brown, A.J. Kidnay and E.D. Sloan, J. Chem.Eng. Data 40, 726 (1995).

[64] J. Davalos, W.R. Anderson, R.E. Phelps and A.J. Kidnay, J. Chem. Eng. Data 21, 81 (1976).

[65] S. S. Al-Marri, PVT and phase behavior and viscosity measurements and modeling of the ternary and binary systems of carbon dioxide + heavy hydrocarbon (n-eicosane) + light gas (ethane or propane). PhD thesis, University of Southern California, May (2006).

[66] R. Span, W. Wagner, J. Phys. Chem. Ref. Data 25, 1509 (1996).

[67] Ph. Sentenac, Ch. Berro, E. Rauzy, I. Mokbel, J. Jose, J. Chem. Eng. Data, 49, 1577 (2004).

[68] A. Razzouk, R. A. Naccoul, I. Mokbel, P. Duchet-Suchaux, J. Jose, E. Rauzy, C. Berro, J. Chem. Eng. Data 55, 1468 (2010).

[69] I. Mokbel, C. Lindemann, P. Duchet-Suchaux, J. Jose Fuel 163, 17 (2016).

[70] A. Waheed, M.P. Breil, P. Theveneau, A.H. Mohammadi, G.M. Kontogeorgis, and D. Richon. Ind. Eng. Chem. Res. 48, 11202 (2009).

[71] G. Kontogeorgis, I. Tsivintzelis, M.L. Michelsen, E.H. Stenby, Fluid Phase Equilib. 301, 244 (2011).

[72] S.O. Derawi, G.M. Kontogeorgis, E.H. Stenby, T. Haugum, A.O. Fredheim, J. Chem. Eng. Data 47, 169 (2002).

[73] S.O. Derawi, G.M. Kontogeorgis, M.L. Michelsen and E.H. Stenby, Fluid Phase Equilib. 209, 163 (2003).

[74] S.O. Derawi, G.M. Kontogeorgis, M.L. Michelsen and E.H. Stenby, Ind. Eng. Chem. Res. 42, 1470 (2003).

[75] C. Tsonopoulos, G.M. Wilson, AIChE J. 29, 990 (1983).

[76] I. Tsivintzelis, G.M. Kontogeorgis, J. Chem. Thermodynamics, 93, 305 (2016).

[77] I. Tsivintzelis, G.M. Kontogeorgis, Ind. Eng. Chem. Res. 51, 13496 (2012).

[78] I. Tsivintzelis, A. Shahid, G.M. Kontogeorgis, Fluid Phase Equilibria, 430, 75 (2016).

[79] A.J. Haslam, A. Galindo, G. Jackson, Fluid Phase Equilib. 266, 105 (2008).

[80] M.P. Breil, I. Tsivintzelis, G.M. Kontogeorgis, Fluid Phase Equilib. 301, 1 (2011) 
[81] N. Von Solms, M.L .Michelsen, and G.M. Kontogeorgis, Ind. Eng. Chem. Res. 43, 1803 (2004).

[82] S.A. Avlund, G.M. Kontogeorgis, M.L. Michelsen, Ind. Eng. Chem. Res. 47, 7441 (2008).

[83] T.Wang, E. El Ahmar, C. Coquelet, Fluid Phase Equilibria, 434, 93 (2017)

[84] A.S. Avlund, G.M. Kontogeorgis, W.G. Chapman, Mol. Physics, 109, 1759 (2011).

[85] R.P. Sear, G. Jackson, Phys. Rev. E 50 (1), 386 (1994)

[86] D. Ghonasgi and W.G. Chapman, J. Chem. Phys. 102 (6), 2585 (1995).

[87] A.S. Avlund, G.M. Kontogeorgis, M.L. Michelsen, Industrial \& Engineering Chemistry Research, 51(1), 547 (2012)

[88] A. Arya, X. Liang, N. von Solms, G.M. Kontogeorgis, Energy \& Fuels, 30, 6835 (2016).

[89] D.L.Gonzalez, P.D.Ting, G.J.Hirasaki, W.G.Chapman, Energy \& Fuels, 19, 1230 (2005)

[90] D.L.Gonzalez, F.M. Vargas, G.J.Hirasaki, W.G.Chapman, Energy \& Fuels, 22, 757 (2008)

[91] M.G. Bjorner, A.A. Shapiro, G.M. Kontogeorgis, Ind. Eng. Chem. Res., 52, 2672 (2013).

[92] S. Bartholdy, M.G. Bjorner, E. Solbraa, A. Shapiro, G.M. Kontogeorgis, Ind. Eng. Chem. Res. 52, 11552 (2013).

[93] X. Liang, M.L. Michelsen, G.M. Kontogeorgis, Fluid Phase Equilib. 428, 153 (2016).

[94] X.D. Liang, M.L. Michelsen, G.M. Kontogeorgis, Fluid Phase Equilib. 415, 75 (2016).

[95] B.D. Marshall, K.R.Cox, W.G.Chapman, J.Phys.Chem.C, 116(33), 17641 (2012)

[96] J. Mairhofer, J. Gross, Fluid Phase Equilibria, 439, 31 (2017) 